\title{
FGF23 expression is stimulated in transgenic $\alpha$-Klotho longevity mouse model
}

\author{
Zhousheng Xiao,, ${ }^{1}$ wendalyn King, ${ }^{2}$ Salvatore Mancarella, ${ }^{3}$ Undral Munkhsaikhan, ${ }^{4}$ Li Cao, \\ Chun Cai, ${ }^{1}$ and Leigh Darryl Quarles ${ }^{1}$ \\ 'Department of Medicine, University of Tennessee Health Science Center, Memphis, Tennessee, USA. ${ }^{2}$ Department \\ of Biology, Creighton University, Omaha, Nebraska, USA. ${ }^{3}$ Department of Physiology and ${ }^{4}$ Department of Pediatrics, \\ University of Tennessee Health Science Center, Memphis, Tennessee, USA.
}

\begin{abstract}
Observations in transgenic $\alpha-K l o t h o(K I)$ mice $\left(K \Gamma^{\mathrm{s}}\right)$ defined the antiaging role of soluble Klotho $\left(\mathrm{sKL}^{130}\right)$. A genetic translocation that elevates sKL levels in humans is paradoxically associated with increased circulating fibroblast growth factor 23 (FGF23) levels and the potential of both membrane $\mathrm{KL}\left(\mathrm{mKL} \mathrm{L}^{135}\right.$ ) and $\mathrm{sKL} \mathrm{L}^{130}$ to act as coreceptors for FGF23 activation of fibroblast growth factor receptors (FGFRs). Neither FGF23 expression nor the contributions of FGF23, mKL ${ }^{135}$, and SKL ${ }^{130}$ codependent and independent functions have been investigated in $K \Gamma^{\mathrm{Tg}}$ mice. In the current study, we examined the effects of $K /$ overexpression on FGF23 levels and functions in $K \Gamma^{T s}$ mice. We found that $\mathrm{mKL}^{135}$ but not sKL ${ }^{130}$ stimulated FGF23 expression in osteoblasts, leading to elevated Fgf23 bone expression and circulating levels in $K \Gamma^{\mathrm{Ig}}$ mice. Elevated FGF23 suppressed 1,25(OH) $\mathrm{D}$ and parathyroid hormone levels but did not cause hypophosphatemic rickets in $K \Gamma^{\mathrm{tg}}$ mice. $K \Gamma^{\mathrm{Ts}}$ mice developed low aldosterone-associated hypertension but not left ventricular hypertrophy. Mechanistically, we found that $\mathrm{mKL}^{135}$ and sKL ${ }^{130}$ are essential cofactors for FGF23-mediated ERK activation but that they inhibited FGF23 stimulation of PLC- $\gamma$ and PI3K/AKT signaling. Thus, increased longevity in $K^{\top \mathrm{s}}$ mice occurs in the presence of excess FGF23 that interacts with $\mathrm{mKL}$ and sKL to bias FGFR pathways.
\end{abstract}

Conflict of interest: The authors have declared that no conflict of interest exists.

Copyright: (ㄷ) 2019, American Society for Clinical Investigation.

Submitted: August 19, 2019 Accepted: October 23, 2019 Published: December 5, 2019.

Reference information: /CI Insight. 2019;4(23):e132820. https://doi.org/10.1172/jci. insight.132820.

\section{Introduction}

It is widely accepted that $\alpha$-Klotho (KL) functions as an aging suppressor gene in mice (1), largely based on a seminal publication showing that $\mathrm{KL}$ extends life span when transgenically overexpressed in mice (1). $K l$-transgenic $\left(K l^{\mathrm{Ig}}\right)$ mice were created by overexpression of the $K l \mathrm{cDNA}$ that encodes the transmembrane protein with KL1 and KL2 domains under control of the human elongation factor 1a (hEF1a) promoter. The development of a premature aging-like syndrome when $K l$ is disrupted in mice further supports the role of $\mathrm{KL}$ in longevity (2). The $K L$ gene generates 2 transcripts in mammals, a full-length $K L$ mRNA that encodes a single-pass $135-\mathrm{kDa}$ transmembrane cell surface protein with extracellular KL1 (Glu34 to Phe506) and KL2 (Leu515 to Ser950) domains (designated $\mathrm{mKL}^{135}$ ) (3). An alternative spliced mRNA that encodes only a KL1-like domain $\left(\mathrm{sKL}^{70}\right)$ is not translated in humans $(4,5)$ but is found in the mouse brain $(6,7)$. Rather,

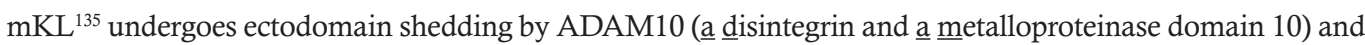
ADAM17 metalloproteinases to generate a circulating isoform of about $130 \mathrm{kDa}\left(\mathrm{sKL}^{130}\right)$ that contains the KL1 and KL2 domains $(8,9)$. Soluble circulating Klotho (sKL) is detected in serum (10), urine (11), and cerebrospinal fluid (ref. 12; see supplemental data and Supplemental Figure 1 for nomenclature; supplemental material available online with this article; https://doi.org/10.1172/jci.insight.132820DS1).

The increased longevity in $K l^{\mathrm{Tg}}$ mice was originally attributed to functions of sKL to inhibit insulin and insulin-like growth factor (IGF) signaling. This hypothesis is consistent with the fact that Klotho orthologs in Caenorhabditis elegans encode only KL1 domain-like proteins that inhibit DAF-2, which is homologous to IGF-1 signaling in mammals (13). Additional studies found that sKL inhibits TNF- $\alpha$, IGF-1, Wnt, and TGF- $\beta$ signaling $(1,14-18)$. In addition, $\mathrm{sKL}$ is proposed to bind to gangliosides containing $\alpha-2$-3-sialyllactose in lipid rafts to inhibit PI3K signaling (19), as well as regulate calcium-permeable transient receptor potential canonical type isoform 6 (TRPC6) channels (20).

The mechanisms whereby KL exerts antiaging effects, however, warrant reexamination based on new knowledge that both transmembrane $\left(\mathrm{mKL}^{135}\right)$ and soluble Klotho $\left(\mathrm{sKL}^{130}\right)$ act as coreceptors for 
the hormone FGF23, which regulates mineral and cardiovascular homeostasis. FGF23 is a b1-derived hormone whose principal function is to regulate phosphate and $1,25(\mathrm{OH})_{2} \mathrm{D}$ metabolism (21-24). Structural models show that the N-terminus of FGF23 and the KL2 domain of mKL ${ }^{135}$ interact with FGF receptors (FGFRs) 1c, 3c, or 4, and the C-terminus of FGF23 binds to a pocket created by the KL1 and KL2 domains to form the active ternary canonical FGF23/FGFR/KL receptor complex $(3,25,26)$. Shed sKL ${ }^{130}$ can also act as a circulating "on-demand, non-enzymatic scaffold" protein that regulates FGF23 signaling (3). The physiological effects of circulating FGF23 are mediated by activation of FGFRs complexed with transmembrane $\alpha$-Klotho (i.e., canonical signaling) (25). The codependency of FGF23 and Klotho is supported by mouse genetic studies showing that $\mathrm{Fg}_{2} 23^{-/-}$and $\mathrm{Kl}^{-/-}$mice are exact phenocopies, characterized by hyperphosphatemia, excess $1,25(\mathrm{OH})_{2} \mathrm{D}_{3}$, soft tissue calcifications, and early mortality $(2,27-29)$. The nonredundant phenotypes are further supported by the fact that $K l^{-1-}$ mice are refractory to FGF23 effects (30-32), and compound mutant $F g f 3$ and $K l$ have nonadditive effects $(27,30-33)$.

On the other hand, the ability of $K l$ overexpression to extend life span is distinct from the effects of excess FGF23, suggesting that the antiaging functions of sKL may be independent from FGF23. Pathological elevation of FGF23 results in hypophosphatemic rickets because of activation of FGFR/ $\mathrm{KL}$ receptor complexes in the kidney tubules, leading to renal phosphate wasting and inhibition of $1,25(\mathrm{OH})_{2} \mathrm{D}_{3}$ production. Excess circulating FGF23 is also linked to increased mortality, cardiovascular disease, and inflammation (34-45). Increased level of FGF23 is a strong predictor of left ventricular hypertrophy (LVH) and mortality in patients with renal disease, as well as in the general population (36-39, 46). A causal role of FGF23 in inducing LVH is supported by genetic and pharmacological models of excess FGF23 $(31,47,48)$. These effects of FGF23 are discordant with function of sKL to increase longevity.

Whether KL functions are truly independent of FGF23, however, is questioned by new data showing that KL regulates FGF23 expression. In this regard, increased circulating sKL ${ }^{130}$ in humans caused by a de novo translocation with a breakpoint adjacent to the $K L$ gene leads to elevations in FGF23 levels (49), suggesting that $\mathrm{sKL}^{130}$ may stimulate FGF23 production. Although conditional deletion of $K l$ in osteoblasts and osteocytes has no effects on $F g f 23$ expression in bone $(50,51)$, overexpression of $s K l^{130}(K l 1$ and Kl2) stimulates $F g f 23$ expression in osteoblasts (52).

Surprisingly, neither the $\alpha$-Klotho isoform expression nor the expression of $F g f 23$ have been examined in $K l^{\mathrm{Tg}}$ mice. If FGF23 is elevated in $K l^{\mathrm{Tg}}$ mice and activates FGFR signaling, additional concepts would be needed to explain why elevated FGF23 did not cause adverse effects in $K l^{T g}$ mice that exhibit an antiaging phenotype. Because of the possibilities that $K l$ overexpression induces $F g f 23$ expression and that sKL modulates FGF23 signaling, we examined FGF23 and sKL expression in the long-lived transgenic $m K l^{135}$ mouse model (1). In addition, to test the FGF23-independent functions of $\mathrm{KL}$, we transferred $K l^{\mathrm{Tg}}$ mice onto Fgf23-null mice. Finally, we reexamined the effects of KL isoforms on FGF23 activation of FGFR-dependent signaling pathways.

\section{Results}

Klotho isoforms' expression in $K l^{T g}$ mice. First, we examined full-length $\left(m K l^{135}\right)$ and alternatively spliced $K l$ $\left(s K l^{70}\right)$ message expression in different tissues in wild-type and $K{ }^{\mathrm{Tg}}$ mice by real-time reverse transcription PCR (RT-PCR) (1). Endogenous $m K l^{135}$ in wild-type mice was highly expressed in the kidney; low levels of $m K l^{135}$ transcripts were also detected in bone and bone marrow $(50,51)$, as well as in heart, spleen, and liver (Figure 1A). In spite of the wide tissue expression of $h E F 1 a$ promoter, we observed significant increases of $m K l^{135}$ transcripts, which represents the combination of the transgene and endogenous gene, only in the kidney and bone of $K l^{\mathrm{Tg}}$ mice compared with wild-type mice (Figure $\left.1 \mathrm{~A}\right)$. In $K l^{\mathrm{Tg}}$ mice, $m K l^{135}$ expression in other tissues, including bone marrow, heart, spleen, and liver, was similar to wild-type mice (Figure 1A). In addition, we found low levels of the alternatively spliced $s K l^{0}$ transcripts in the kidney, tibia, bone marrow, heart, spleen, and liver in wild-type mice (Figure 1B, note different scale) and significant increases in $s K l^{0}$ transcripts in $K I^{\mathrm{Tg}}$ mice compared with wild-type mice in kidney, bone, and heart, suggesting that overexpression of $m K l^{135}$ may have altered $s K l^{00}$ mRNA expression or decay (5).

Next, we examined expression of the $\mathrm{mKL}^{135}(\sim 135 \mathrm{kDa}), \mathrm{sKL}^{130}(\sim 130 \mathrm{kDa})$, and $\mathrm{sKL}^{70}(\sim 70 \mathrm{kDa})$ proteins by Western blot analysis (Figure 1C). The levels of expression of $\alpha$-Klotho proteins were lower in wild-type mice but with bands consistent with $\mathrm{mKL}^{135}$ or $\mathrm{sKL}^{130}\left(\mathrm{KL} 1\right.$ and $\mathrm{KL} 2$ ) and $\mathrm{sKL}^{70}$ (or $\mathrm{sKL} 1^{70}$ ) 
A

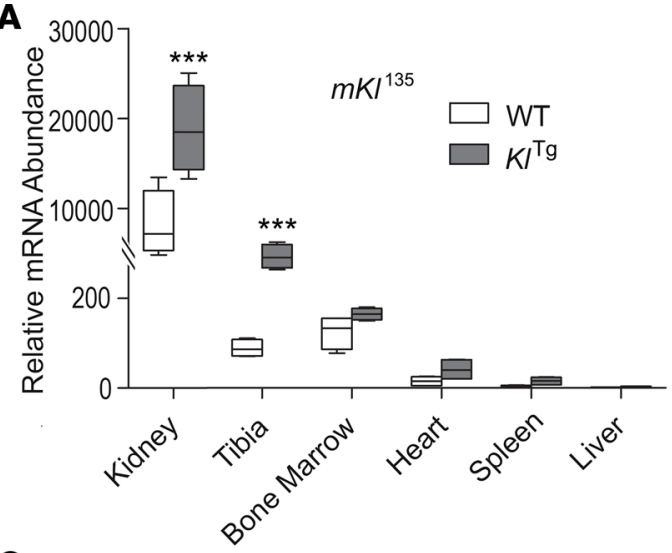

C

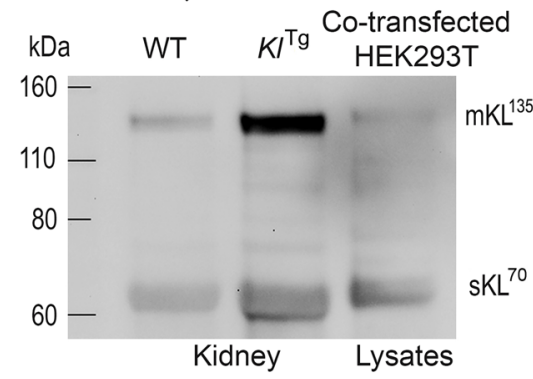

$\beta$-Actin

\section{E}

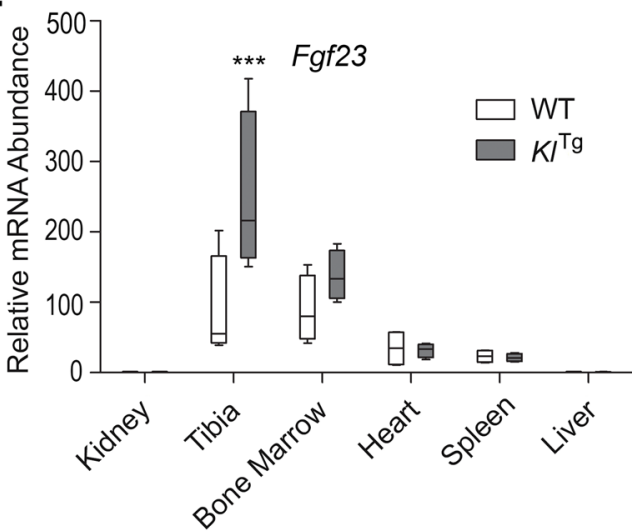

B

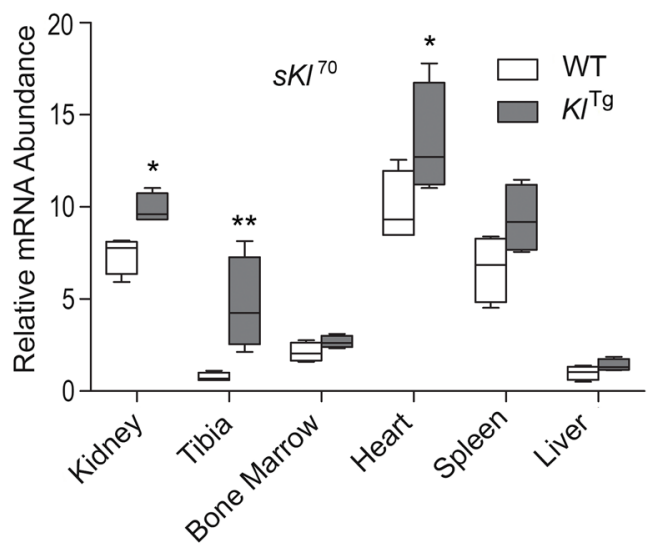

D

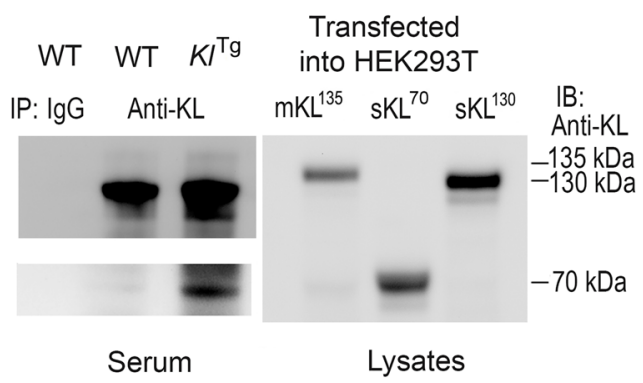

F

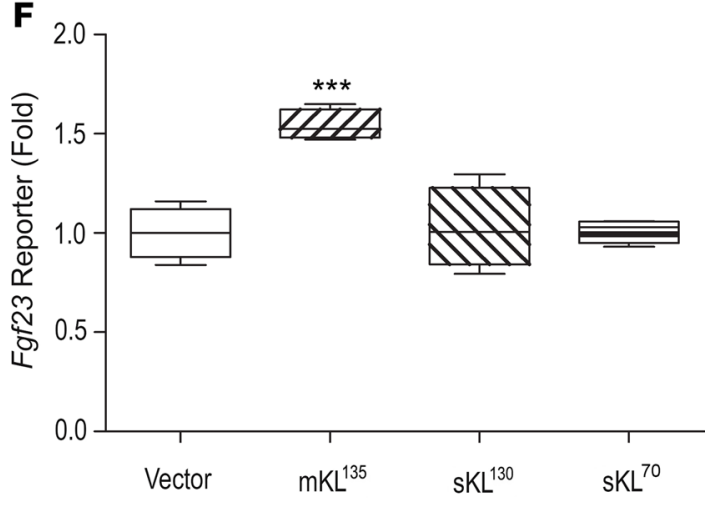

Figure 1. $\boldsymbol{\alpha}$-Klotho isoforms and FGF23 expression in $\boldsymbol{\alpha}$-Klotho-transgenic mice. (A and B) Multiple-tissue real-time RT-PCR analyses for membrane ( $m K L^{135}$, A) and alternative spliced $\left(s K{ }^{70}\right.$, B) Klotho transcripts. (C) Kidney Western blot analysis for mKL $\mathrm{m}^{135} / \mathrm{sKL}^{130}$ and sKL ${ }^{70} / \mathrm{sKL1}^{70}$ protein levels. (D) Serum immunoprecipitation of serum soluble Klotho proteins ( $\left(\mathrm{KL}^{130}\right.$ or $\mathrm{sKL}{ }^{70} / \mathrm{sKL1}^{70}$ ) with anti-Klotho KL1 rat mAb (KL-234). (E) Multiple-tissue real-time RT-PCR analyses for Fgf23 transcripts. (F) Regulation of Fgf23 promoter-luciferase reporter activities by transient overexpression of $\alpha$-Klotho isoforms. Data are expressed as the mean \pm SD from 8-10 mice or 3 independent experiments in triplicate. The box plots depict the minimum and maximum values (whiskers), the upper and lower quartiles, and the median. The length of the box represents the interquartile range. ${ }^{*} P<0.05,{ }^{* *} P<0.01$, and ${ }^{* * *} P<0.001$ versus wild-type or vector alone control group.

in the kidney (Figure 1C). We detected no other protein bands in other tissues (data not shown). In $\mathrm{K}^{\mathrm{T}} \mathrm{g}$ mice, we found strong bands consistent with increased expression of both $\mathrm{mKL}^{135}$ or sKL ${ }^{130}$ (KL1 and $\mathrm{KL} 2$ ) in the kidney. We also observed increased expression of $\mathrm{SKL}^{70}$ or $\mathrm{sKL} 1^{70}$ in the kidney but to a lesser extent (Figure 1C). The $135-\mathrm{kDa}$ band intensity was much greater than the $70-\mathrm{kDa}$ band in the kidney in $K l^{\mathrm{Tg}}$ mice. The antibody used did not detect the KL2 fragment. We also found very weak bands consistent with $\mathrm{mKL}^{135}$ or sKL ${ }^{130}$ (KL1 and $\left.\mathrm{KL} 2\right)$ in the bone, heart, and liver in $\mathrm{Kl}^{\mathrm{Ig}}$ mice. Thus, the magnitude of the increase in $\mathrm{mKL}^{135}$ and its tissue distribution were more limited than expected in $K l^{\mathrm{Tg}}$ mice, given the positive phenotypes affecting multiple organs reported in these mice.

Finally, to measure sKL protein levels in the serum, we performed coimmunoprecipitation (CoIP) with anti-Klotho KL1 rat mAb (KL-234) and used a validated ELISA. In $\mathrm{K}^{\mathrm{Tg}}$ mice, we detected an increase of 
Table 1. Serum biochemistry analysis in 8-week-old mice

\begin{tabular}{|ccc|}
\hline Parameters & Wild-type & $\boldsymbol{K}^{\mathbf{T}}$ \\
\hline FGF23 $(\mathrm{pg} / \mathrm{mL})$ & $85 \pm 25$ & $150 \pm 43^{\mathrm{B}}$ \\
\hline Klotho $(\mathrm{pg} / \mathrm{mL})$ & $347 \pm 58$ & $820 \pm 383^{\mathrm{A}}$ \\
\hline Phosphate $(\mathrm{mg} / \mathrm{dL})$ & $9.4 \pm 0.71$ & $10.1 \pm 0.67$ \\
\hline Calcium $(\mathrm{mg} / \mathrm{dL})$ & $8.4 \pm 0.19$ & $8.6 \pm 0.34$ \\
\hline PTH $(\mathrm{pg} / \mathrm{mL})$ & $230 \pm 95$ & $116 \pm 82^{\mathrm{A}}$ \\
\hline $1,25(\mathrm{OH}){ }_{2} \mathrm{D}(\mathrm{pg} / \mathrm{mL})$ & $168 \pm 72$ & $96 \pm 36^{\mathrm{A}}$ \\
\hline Aldosterone $(\mathrm{pg} / \mathrm{mL})$ & $437 \pm 17$ & $238 \pm 42^{\mathrm{B}}$ \\
\hline
\end{tabular}

Data are mean \pm SD from 8-10 serum samples of 8 -week-old individual mice. ${ }^{A} P<0.05$ versus wild-type. ${ }^{B} P<0.01$ versus wild-type.

soluble $\alpha$-Klotho protein, including $\mathrm{sKL}^{130}$ (KL1 and $\mathrm{KL} 2$ ) and $\mathrm{sKL}^{70}$ (or sKL1 ${ }^{70}$ ) by CoIP (Figure 1D). In addition, serum sKL levels were more than 2-fold higher in $K l^{\mathrm{Tg}}$ mice compared with controls (Table 1). Collectively, these studies demonstrate that $K l^{\mathrm{Tg}}$ mice have proportionately greater increase in serum sKL compared with tissue $\mathrm{mKL}^{135}$ expression.

FGF23 expression in $\mathrm{Kl}^{T g}$ mice. Next, we examined the effects of overexpression of $m K l^{135}$ on $F g f 23$ expression. We examined $F g f 23$ message expression in various tissues (Figure 1E). $F g f 23$ is predominately expressed in bone and bone marrow of wild-type mice, where Fgf23 is known to be expressed in the osteoblasts/osteocytes and in endothelial cells of the bone marrow venous sinusoids, respectively (53). We also detected lowlevels of Fgf 23 transcripts in the heart and spleen but not in the kidney or liver of wild-type mice. In $K^{\mathrm{Tg}}$ mice, we found a significant increase of Fgf 23 transcripts in both bone and bone marrow samples but not in other tissues (Figure 1E). This was accompanied by a 2-fold elevation of serum FGF23 in the $K l^{\mathrm{Tg}}$ mice (Table 1).

To explore the relative contributions of $\alpha$-Klotho isoforms to the increased $F g f 23$ expression in the $K l^{\mathrm{Tg}}$ mice, we cotransfected cDNAs for each of the $m K l^{135}, s K l^{130}$ (KL1 and $\left.K L 2\right)$, and $s K l^{70}$ isoforms along with $F g f 23$ reporter construct in MC3T3-E1 osteoblasts. Surprisingly, only transient overexpression of $m K l^{135}$ isoform showed stimulatory effects on $F g f 3$ reporter activity compared with empty vector control (Figure $1 \mathrm{~F}$ ). Neither $s K l^{130}$ (KL1 and KL2) nor $s K l^{0}$ stimulated $F g f 23$ reporter activity in this in vitro model (Figure $1 F)$, suggesting canonical activation of FGFR1 and membrane $\alpha$-Klotho overexpression in osteoblasts may account for the increased FGF23 levels in the $\mathrm{Kl}^{\mathrm{Tg}}$ mice.

Serum parameters and kidney gene profiles in $K l^{T g}$ mice. We then examined biological effects of excess FGF23, mKL ${ }^{135}$, and sKL in $K l^{\mathrm{Tg}}$ mice. We did not attempt to verify the increased longevity and other antiaging phenotypes that are well documented in the $K l^{\mathrm{Ig}}$ model (1) but focused on FGF23-dependent effects. The 2-fold increase in FGF23 was not associated with alterations in serum phosphate and calcium, which were not different between wild-type and $K l^{\mathrm{Ig}}$ mice (Table 1). However, both parathyroid hormone $(\mathrm{PTH})$ and $1,25(\mathrm{OH})_{2} \mathrm{D}$ levels were significantly reduced in the $K \mathrm{I}^{\mathrm{Ig}}$ mice (Table 1$)$. In addition, we found that serum aldosterone levels in the $K l^{\mathrm{Tg}}$ mice were much lower than those in wild-type control mice. These biochemical changes are consistent with known effects of FGF23 to target FGFR/KL binary complexes

Table 2. Gene expression profiles in the kidney in 8-week-old mice

\begin{tabular}{ccc}
\hline Gene & Wild-type & $\boldsymbol{K}^{\mathrm{Tg}}$ \\
Fgfr1 & $1.00 \pm 0.11$ & $1.01 \pm 0.29$ \\
Npt2a & $1.00 \pm 0.14$ & $1.11 \pm 0.46$ \\
Npt2c & $1.00 \pm 0.22$ & $0.53 \pm 0.19^{\mathrm{A}}$ \\
Klotho & $1.00 \pm 0.15$ & $1.58 \pm 0.22^{\mathrm{B}}$ \\
Cyp24a1 & $1.00 \pm 0.30$ & $1.57 \pm 0.32^{\mathrm{A}}$ \\
Cyp27b1 & $1.00 \pm 0.27$ & $0.67 \pm 0.11^{\mathrm{A}}$ \\
NCC & $1.00 \pm 0.23$ & $2.13 \pm 0.47^{\mathrm{B}}$
\end{tabular}

Data are mean \pm SD from 8-10 kidneys of 8-week-old individual mice and expressed as the fold changes relative to the housekeeping gene $\beta$-actin subsequently normalized to control mice. ${ }^{A} P<0.05$ versus wild-type. ${ }^{B} P<0.001$ versus wild-type. 
A

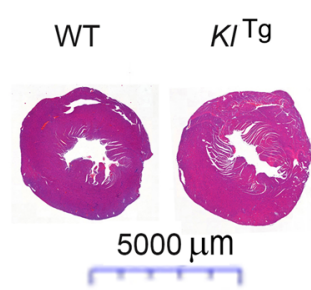

Heart H\&E staining
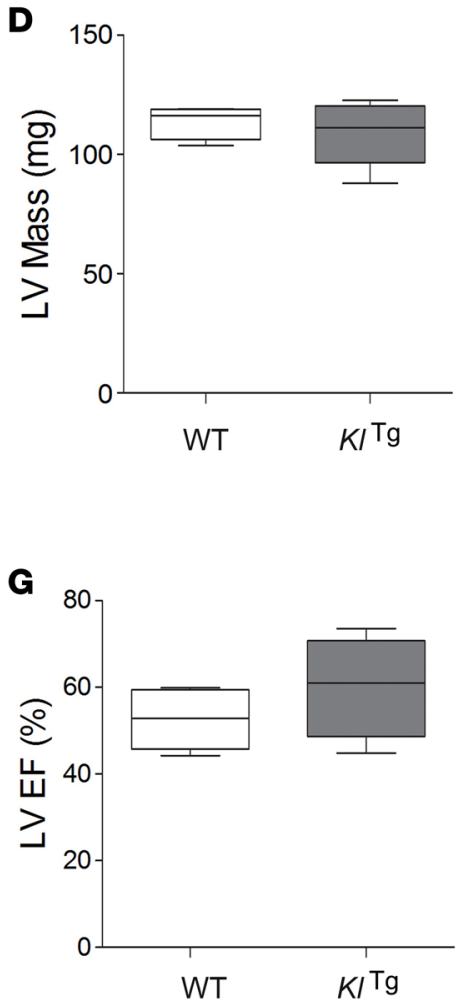
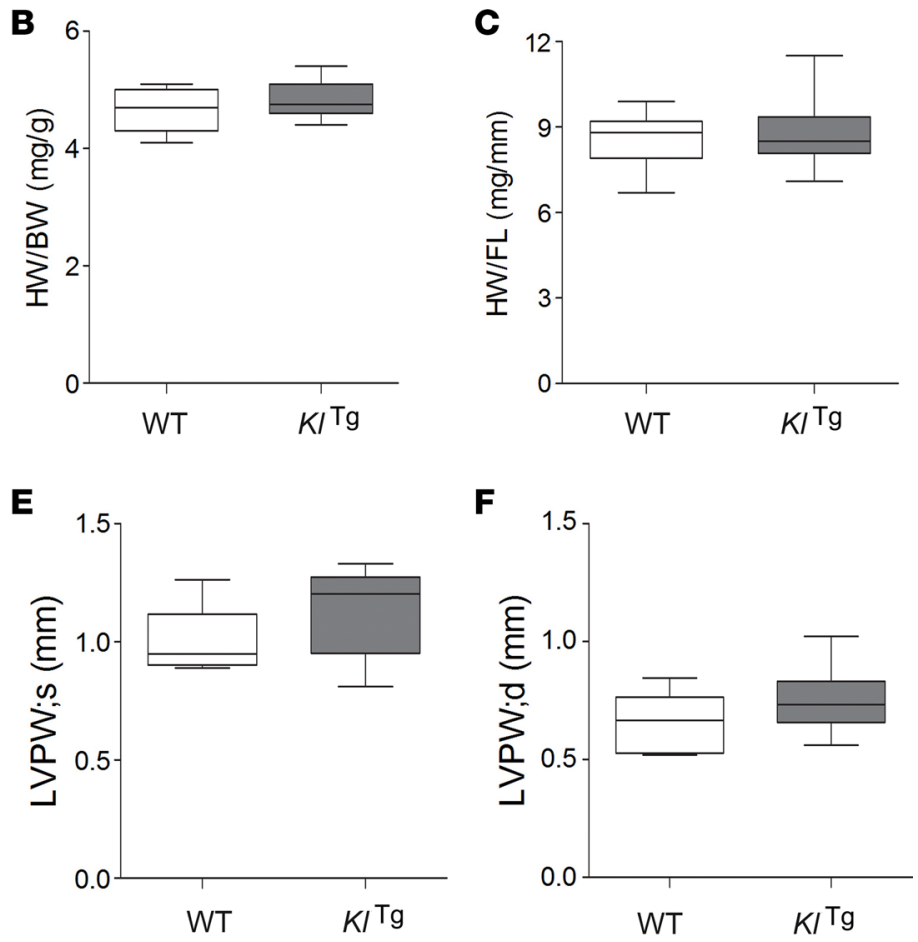

Figure 2. Heart and blood pressure phenotypes in $\boldsymbol{K}^{\Gamma^{\mathrm{s}}}$ mice. (A) Cross sections of the heart in H\&E staining. (B and C) Heart weight/body weight (HW/BW) and heart weight/femur length (HW/FL) ratios. (D-C) Echocardiography for cardiac function. LVPW; s, left ventricular posterior wall thickness at end-systole; LVPW; d, left ventricular posterior wall thickness at end-diastole; LVEF, left ventricular ejection fraction. (H) Blood pressure (BP) measurement. SBP, systolic BP; DBP, diastolic BP; MBP, mean BP. Data are expressed as the mean \pm SD from 8-10 mice. The box plots depict the minimum and maximum values (whiskers), the upper and lower quartiles, and the median. The length of the box represents the interquartile range. ${ }^{* *} P<0.01$ versus wild-type control mice.

in the proximal tubule to suppress $1,25(\mathrm{OH})_{2} \mathrm{D}$ production (28) and in the distal tubule to increase sodium reabsorption (54), as well as possible effects of FGF23 and $\alpha$-Klotho to suppress PTH expression and secretion in the parathyroid gland $(55,56)$.

In addition, the $\mathrm{Kl}^{\mathrm{Ig}}$ mice exhibited alterations in FGF23-responsive genes in the kidney that regulate 1,25(OH) 2 D metabolism, including decrements in Cyp27b1, which controls synthesis, and increments in Cyp24a1, which controls catabolism of $1,25(\mathrm{OH})_{2} \mathrm{D}$ and sodium chloride cotransporter $(\mathrm{NCC})$, which maintains body $\mathrm{Na}^{+}$ and $\mathrm{K}^{+}$homeostasis. The sodium/phosphate cotransporters located in the proximal convoluted tubule were not changed whereas the downstream sodium-dependent phosphate cotransporter $2 \mathrm{c}(\mathrm{Npt2c})$ located in the proximal straight tubule was decreased 2-fold in the $K l^{\mathrm{Ig}}$ mice (Table 2). Failure to reduce the upstream Npt2a mRNA may account for the absence of hypophosphatemia and may reflect the effects of reduced PTH that offset the increased FGF23 renal effects. There were no differences in Fgfrl transcripts between wild-type and $\mathrm{Kl}^{\mathrm{T} g}$ mice.

Cardiovascular parameters and heart gene profiles in $\mathrm{Kl}^{T_{8}}$ mice. FGF23 excess can induce LVH through direct activation of FGFR4 in the heart and indirect effects on the kidney to increase sodium reabsorption, leading 
Table 3. Gene expression profiles in the heart in 8-week-old mice

\begin{tabular}{ccc}
\hline Gene & Wild-type & $\boldsymbol{K} \boldsymbol{T}^{\mathbf{g}}$ \\
$\alpha-K L$ & $1.00 \pm 0.19$ & $4.21 \pm 1.56^{\mathrm{C}}$ \\
$\alpha-S M A$ & $1.00 \pm 0.25$ & $0.50 \pm 0.28^{\mathrm{A}}$ \\
\hline ANP & $1.00 \pm 0.20$ & $0.52 \pm 0.19^{\mathrm{A}}$ \\
$B N P$ & $1.00 \pm 0.17$ & $0.56 \pm 0.18^{\mathrm{A}}$ \\
$\beta$-MHC & $1.00 \pm 0.23$ & $0.65 \pm 0.17^{\mathrm{A}}$ \\
$\alpha-M H C$ & $1.00 \pm 0.22$ & $0.93 \pm 0.29$ \\
Coll & $1.00 \pm 0.21$ & $0.53 \pm 0.23^{\mathrm{B}}$ \\
CTGF & $1.00 \pm 0.20$ & $0.63 \pm 0.11^{\mathrm{A}}$ \\
Vimentin & $1.00 \pm 0.18$ & $0.67 \pm 0.14^{\mathrm{A}}$ \\
TGF- $\beta$ & $1.00 \pm 0.28$ & $0.58 \pm 0.10^{\mathrm{B}}$ \\
Snail1 & $1.00 \pm 0.24$ & $0.57 \pm 0.14^{\mathrm{B}}$ \\
\hline
\end{tabular}

Data are mean \pm SD from 8-10 kidneys of 8-week-old individual mice and expressed as the fold changes relative to the housekeeping gene $\beta$-actin subsequently normalized to control mice. ${ }^{A} P<0.05$ versus wild-type. ${ }^{B} P<0.01$ versus wildtype. ${ }^{c} P<0.001$ versus wild-type.

to hypertension $(46,47,57)$. In contrast, sKL can prevent LVH caused by angiotensin II-induced cardiac hypertrophy $(58,59)$. Therefore, we investigated whether $K l^{\text {Ig }}$ mice exhibited cardiovascular abnormalities.

We observed no significant changes of heart weight/body weight (HW/BW) or heart weight/femur length (HW/FL) ratio between $K l^{\mathrm{Ig}}$ and wild-type control mice (Figure 2, A-C). Echocardiographs showed that $K l^{\mathrm{Ig}}$ mice had no differences in left ventricular (LV) mass, left ventricular posterior wall (LVPW) thickness at end-systole, LVPW at end-diastole, and left ventricular ejection fraction (LVEF) at baseline compared to wild-type mice (Figure 2, D-G). Consistent with the absence of $\mathrm{LVH}$ in $\mathrm{Kl}^{\mathrm{rg}}$ mice, real-time RT-PCR analysis revealed that the heart in the $K l^{\mathrm{Ig}}$ mice displays downregulation of LVH-related genes' expression (i.e., $\alpha-S M A, A N P, B N P$, and $B M H C$ ) as well as cardiac fibrosis and epithelial-mesenchymal transition genes' expression (i.e., ColI, CTGF, Vimentin, TGFB, and Snaill) (Table 3).

In contrast, blood pressure, including systolic BP, diastolic BP, and mean BP, were significantly higher in $K l^{\mathrm{Ig}}$ compared with wild-type mice (Figure $2 \mathrm{H}$ ). Thus, neither elevated FGF23 level or blood pressure induced $\mathrm{LVH}$ in $\mathrm{Kl}^{\mathrm{Ig}}$ mice, consistent with the purported protective function of $\alpha$-Klotho in the heart (Table 3).

Skeletal phenotypes and bone gene profiles in $\mathrm{Kl}^{T g}$ mice. Because of recent studies showing that $\alpha$-Klotho inhibits bone mineralization $(50,51)$, we investigated the bone phenotype of $K^{\mathrm{Tg}}$ mice. At 8 weeks of age, the gross appearance and $\mathrm{BW}$ of wild-type and $K l^{\mathrm{Tg}}$ mice were indistinguishable. Compared to wild-type mice, $K l^{\mathrm{Ig}}$ mice exhibited no abnormalities in bone mass as evidenced by normal bone mineral density (BMD) in both male and female adult mice (Figure 3A). Micro-CT analysis revealed that there was no difference in trabecular bone volume, cortical bone thickness, or growth plate appearance of $K l^{\mathrm{Ig}}$ mice compared to wild-type mice (Figure 3B). Consistent with a normal bone mass and structure by BMD and micro-CT analysis, we found that there was no change in periosteal MAR between wild-type and $K^{I^{\mathrm{g}} \mathrm{g}}$ mice (Figure 3C), indicating a normal bone formation rate in $K l^{\mathrm{Tg}}$ mice.

Next, we examined by real-time RT-PCR the expression levels of a panel of osteoblast lineage-, osteoclast-, chondrocyte-, and adipocyte-related mRNAs from the femurs of 8-week-old wild-type and $K l^{\mathrm{Tg}}$ mice (Table 4). The $K l^{\mathrm{Ig}}$ mice did exhibit higher expression of $m K l^{35}$ and $F g f 23$ transcripts, as we described above. However, we did not observe significant alterations in osteoblast lineage-, osteoclast-, or chondrocyte-related gene expression (Table 4). We found significant reductions of only Osteocalcin and Osteopontin mRNA levels in the $K I^{\mathrm{Tg}}$ mice compared with wild-type mice. Unexpectedly, Pparg, an adipocyte transcription factor, and adipocyte markers, including lipoprotein lipase $(L p l)$ and adipocyte fatty acid-binding protein $2(a P 2)$, were significantly increased in the long bones of $\mathrm{Kl}^{\mathrm{Tg}}$ mice, indicating overexpression of $m K l^{135}$ enhanced adipogenesis in bone marrow of $K l^{\mathrm{Ig}}$ mice. These findings are consistent with the promotion of adipogenesis by $m K l^{135}(60,61)$.

Compound Fgf23 knockout and $\mathrm{Kl}^{\mathrm{Ig}}$ mice. To look for a survival benefit in $\mathrm{Kl}^{\mathrm{Ig}}$ mice and for FGF23-independent effects, we overexpressed $m \mathrm{Kl}^{35}$ in $\mathrm{Fg} f 23$-deficient mice. $\mathrm{Kl}^{\mathrm{Ig}} \mathrm{Fg} 2 \mathrm{3}^{+/-}$mice were mated with $\mathrm{Kl}^{\mathrm{Ig}}$ $\mathrm{Fg} f 23^{+/-}$mice to generate wild-type, $\mathrm{KI}{ }^{\mathrm{Ig}}, \mathrm{Fg} f 2^{-{ }^{--}}$, and $\mathrm{KI}^{\mathrm{Ig}} \mathrm{Fg} f 2^{-3^{--}}$with the expected Mendelian frequency. $K l^{\mathrm{Ig}}$ mice developed normally, identically to wild-type littermates during 8 weeks. In contrast, $\mathrm{Fg} f \mathrm{2}^{-1-}$ mice exhibited growth retardation at 8 weeks of age; their body size and BW were significantly smaller and 
A

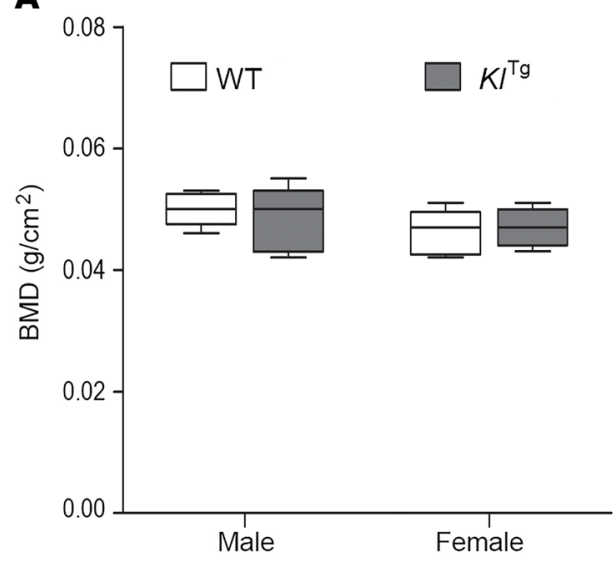

B

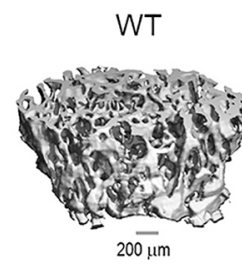

$\mathrm{BV} / \mathrm{TV}(\%) \quad 34+5.2$

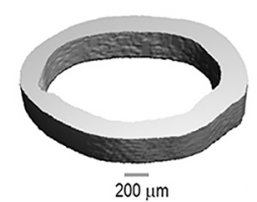

Ct.Th (mm) $\quad 0.18 \pm 0.017$

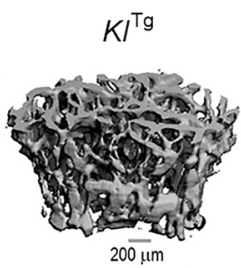

$30 \pm 4.0$

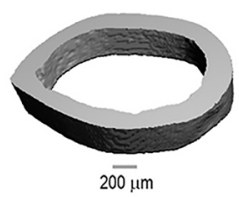

$0.16 \pm 0.011$

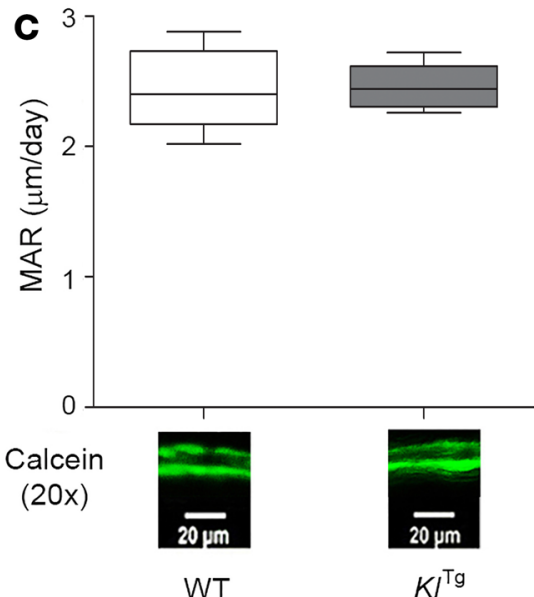

Figure 3. Bone phenotypes in $K \Gamma^{\top 5}$ mice. Effects of $m K L^{135}$ transgene on bone mineral density (BMD) (A), structure of femurs (B), and periosteal mineral apposition rate $(M A R)($ C). Original magnification, $\times 20$. Data are expressed as the mean \pm SD from $8-10$ mice. The box plots depict the minimum and maximum values (whiskers), the upper and lower quartiles, and the median. The length of the box represents the interquartile range. Ct.Th, cortical thickness.

lower, respectively, than wild-type littermates (Figure 4A). The $\mathrm{Fg} f 2^{-1-}$ mice began to die after weaning at 4 weeks of age; no mice could survive beyond 10 weeks. Transferring a Fgf23-null background onto $K l^{\mathrm{Ig}}$ mice did not improve BW and percentage of survival in compound $\mathrm{Fg} f 23$-null and $\mathrm{K} l^{\mathrm{Tg}}$ mice (Figure 4B), suggesting that overexpression of $m K l^{135}$ alone could not rescue the Fgf23-null phenotype without the FGF23 ligand and that non-FGF23-dependent effects of $\mathrm{mKL}{ }^{135}$ cannot be examined in this study.

FGF23-dependent function of $\alpha$-Klotho isoforms in vitro. Finally, we tested the "on-demand" hypothesis that sKL can support FGF23 activation of FGFRs by comparing the ability of $\mathrm{mKL}^{135}$ and sKL ${ }^{130}$ to act as cofactors for FGFR-coupled activation of ERK, PLC- $\gamma$, and PI3K/AKT pathways (48). For these studies, HEK293T cells, which endogenously express FGFRs but not $\alpha$-Klotho (62), were transfected with either empty vector or human $\alpha$-Klotho isoform cDNAs $\left(m K L^{135}, s K L^{130}, s K L 1^{70}, s K L 2^{60}\right.$, or $\left.s K L^{70}\right)$. An ERK reporter construct was used to measure the FGF23/FGFR/KL-ERK signal transduction system in vitro (Figure $5 \mathrm{~A}$ ). The KL-transfected cells were treated with recombinant FGF23 (rFGF23) and heparan sulfate (HS) to examine, respectively, the $\alpha$-Klotho and HS-dependent FGFR activation by FGF23. We also cotransfected HEK293T cells with TACE cDNA, which encodes ADAM17, to test the effects of ectodomain shedding on $\mathrm{mKL}^{135}$ functions. In addition, the HEK293T cells transfected with ERK reporter were treated with human recombinant Klotho ( $\mathrm{rKL}$ ) protein to compare to the corresponding transfected $\mathrm{sKL}^{130} \mathrm{cDNA}$, in the presence of $\mathrm{rFGF} 23$ and HS.

As shown in Figure 5B, HEK293T cells overexpressing $m K L^{135}$ exhibited a robust (about 8-10 fold) increase in ERK activation in response to FGF23 plus HS, consistent with the known canonical FGF23/ FGFR/mKL ${ }^{135}$ signaling pathway. The response to $\mathrm{sKL}^{130}$, however, resulted in a significantly smaller increase in ERK activity (about 2-3 fold) in response to FGF23. Thus, we show for the first time to our knowledge quantitative differences between membrane and circulating Klotho's ability to activate ERK signaling. HEK293T cells transfected with $s K L 1^{70}, s K L 2^{60}$, or $s K L^{70}$ isoforms exhibited no enhancement of FGF23 stimulation of ERK activity, indicating that KL1 and KL2 domains are required for FGF23 activation of FGFR/ERK signaling, as suggested by the 3D structural data (3). Overexpression of ADAM17 significantly reduced the effects of cotransfected $m K L^{135}$ to enhance FGF23-mediated ERK activation, consistent with effects of ectodomain shedding to reduce canonical FGF23/FGFR/mKL ${ }^{135}$-dependent ERK signaling (Figure 5C).

Next we tested the effects of rKL in vitro. As previously reported (62), recombinant FGF23 plus HS exhibited a low but significant stimulation of ERK reporter activity in the absence of rKL. Treatment of rKL led to a modest stimulation of FGF23 signaling (about $2-3$ fold, Figure 5D) similar to $s K L^{130}$ transient transfection, suggesting that $\mathrm{rKL}$ (KL1 and KL2) can only partially reconstitute canonical FGF23/FGFR/ $\mathrm{mKL}^{135}$ signaling imparted by $\mathrm{mKL}^{135}$. These data suggest that $\mathrm{mKL}^{135}$ with its transmembrane and intact $\mathrm{KL} 1$ and KL2 domains is necessary for optimal FGF23 activation of FGFRs, whereas neither the KL1 nor the KL2 domain is sufficient to support canonical FGF23 signaling. 
Table 4. Gene expression profiles in bone in 8-week-old mice

\begin{tabular}{|c|c|c|c|}
\hline Gene & Accession no. & Wild-type & $K \Gamma^{T g}$ \\
\hline \multicolumn{4}{|c|}{ Osteoblast lineage } \\
\hline Klotho & NM_013823.2 & $1.00 \pm 0.24$ & $42 \pm 25^{B}$ \\
\hline FGF-23 & NM_022657.4 & $1.00 \pm 0.37$ & $4.1 \pm 1.9^{B}$ \\
\hline Phex & NM_011077.2 & $1.00 \pm 0.22$ & $0.86 \pm 0.11$ \\
\hline Dmp1 & NM_016779.2 & $1.00 \pm 0.37$ & $0.99 \pm 0.44$ \\
\hline Sost & NM_024449.5 & $1.00 \pm 0.27$ & $0.91 \pm 0.21$ \\
\hline OPG & NM_008764.3 & $1.00 \pm 0.29$ & $0.90 \pm 0.43$ \\
\hline RanKL & NM_011613.3 & $1.00 \pm 0.58$ & $0.99 \pm 0.25$ \\
\hline$A L P$ & NM_011613.3 & $1.00 \pm 0.23$ & $0.97 \pm 0.27$ \\
\hline Osteocalcin & NM_007541.2 & $1.00 \pm 0.29$ & $0.59 \pm 0.16^{A}$ \\
\hline Osteopontin & NM_009263.3 & $1.00 \pm 0.21$ & $0.58 \pm 0.15^{B}$ \\
\hline \multicolumn{4}{|l|}{ Osteoclast } \\
\hline Trap & NM_007388.3 & $1.00 \pm 0.32$ & $0.98 \pm 0.15$ \\
\hline Mmpg & NM_013599.3 & $1.00 \pm 0.28$ & $0.88 \pm 0.31$ \\
\hline \multicolumn{4}{|l|}{ Chondrocyte } \\
\hline Collagen II & NM_031163.3 & $1.00 \pm 0.39$ & $1.08 \pm 0.33$ \\
\hline VegfA & NM_009505.4 & $1.00 \pm 0.62$ & $0.94 \pm 0.29$ \\
\hline \multicolumn{4}{|l|}{ Adipocyte } \\
\hline$P P A R \gamma 2$ & EF062476.1 & $1.00 \pm 0.20$ & $1.61 \pm 0.36^{B}$ \\
\hline$a P 2$ & NM_024406.2 & $1.00 \pm 0.19$ & $1.76 \pm 0.73^{A}$ \\
\hline$L p l$ & NM_008509.2 & $1.00 \pm 0.32$ & $1.69 \pm 0.58^{A}$ \\
\hline
\end{tabular}

Data are mean \pm SD from 8-10 tibias of 8-week-old individual mice and expressed as the fold changes relative to the housekeeping gene $\beta$-actin subsequently normalized to control mice. ${ }^{A} P<0.05$ versus wild-type. ${ }^{B} P<0.01$ versus wild-type.

All $\alpha$-Klotho isoforms containing KL1 domain significantly reduced both basal and TNF- $\alpha-$ or FGF23-mediated NF- $\mathrm{BB}$ activation, whereas KL2 had no effect at all (Figure 5, E and F). These findings suggest that the inhibitory effects on both TNF- $\alpha$ and FGF23 signaling reside in the KL1 domain.

To explore why KL1 failed to augment FGF23 activation of ERK, but inhibited NF- $\mathrm{BB}$ activation, we examined the effects of KL isoforms on FGFR activation of PLC- $\gamma$ and PI3K/AKT signaling pathways in response to FGF23. PLC- $\gamma$ signaling, which is upstream of $\mathrm{NF}-\kappa \mathrm{B}$, has been implicated in FGF23-induced LVH (48). Surprisingly, we found that FGF23 activated both PLC- $\gamma$ and PI3K/AKT signaling pathways in HEK293T cells in the absence of transfected KL isoforms (Figure 6). Moreover, transfection of $m K L^{135}, s K L^{130}, s K L^{70}$, or $s K L 1^{70}$ containing KL1 domain inhibited FGF23 activation of PLC- $\gamma$ and PI3K/AKT signaling pathways (Figure 6). $s K L 2^{60}$ transfection did not inhibit FGF23 activation of PLC- $\gamma$ and PI3K/AKT, indicating that this inhibitory activity resides in the KL1 fragment (Figure 6). Collectively, our findings identify both the obligate coreceptor function of KL that is required for FGF23 activation of ERK and a potentially previously unrecognized function of KL to block FGF23-induced PLC- $\gamma$ and PI3K/AKT signaling.

\section{Discussion}

In the current study, we provide a rigorous reassessment of the $K l^{\mathrm{Ig}}$ mouse longevity model in light of new knowledge of FGF23 and $\alpha$-Klotho codependent signaling. This reexamination is warranted because the seminal observations in $K^{\mathrm{Tg}}$ that gave rise to the idea that shed $\alpha$-Klotho is an antiaging hormone did not adequately consider the potential of $\alpha$-Klotho to stimulate FGF23 production by osteoblasts in bone or the impact of the interdependent functions of FGF23, mKL ${ }^{135}$, and sKL on cell signaling.

We found that the $K l^{\mathrm{Ig}}$ mouse model is not a pure model of sKL excess. Rather, $K l^{\mathrm{Tg}}$ is a unique model that has excess $\mathrm{mKL}^{135}$ in multiple tissues and increased circulating concentrations of both FGF23 and $\mathrm{sKL}^{130}$. The phenotype of $\mathrm{Kl}^{\mathrm{Tg}}$, therefore, is likely a composite of increased canonical FGF23/FGFR/ $\mathrm{mKL}^{135}$ signaling as well as FGF23-dependent and -independent effects of sKL ${ }^{130}$.

$K l^{\mathrm{Tg}}$ mice had an increase in FGF23 expression in bone and elevated serum FGF23 levels, which confounds the original interpretation of this as a pure model of sKL excess (1). In addition, we found that transfection 
A

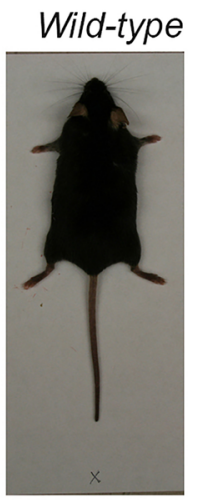

Male $22 \pm 1.0$

Female $18 \pm 0.5$
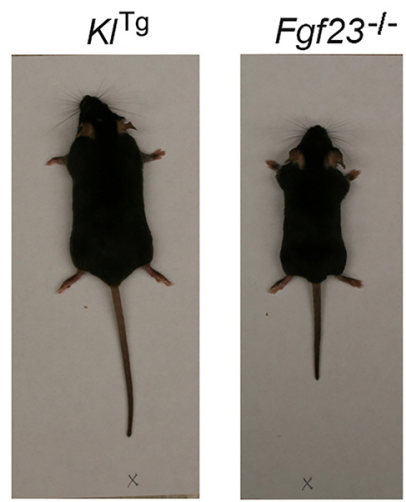

Body weight $(g)$

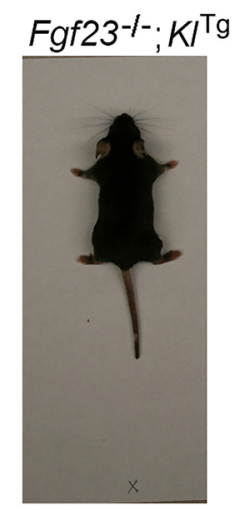

$22 \pm 0.7$

$10 \pm 0.6^{* * *}$

$11 \pm 1.5^{* * *}$

B

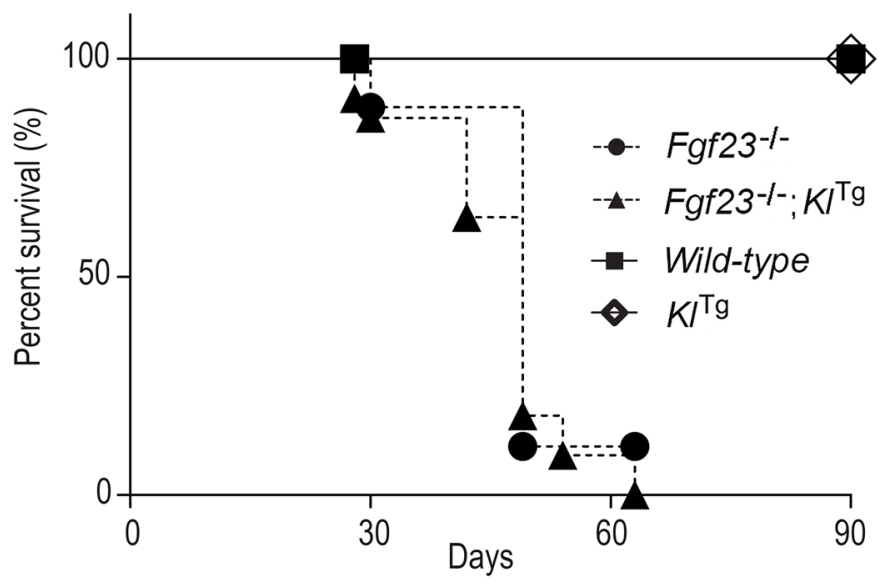

Figure 4. Gross appearance and survival curve in compound Fgf23 knockout and $\boldsymbol{K} \boldsymbol{I}^{\mathrm{Tg}}$ mice. (A) Gross appearance and body weight. (B) Kaplan-Meier survival curve of $F g f 23^{-1-}, K I^{\mathrm{Tg}} \mathrm{Fg} f 23^{-{ }^{--}}$, wild-type, and $\mathrm{K} \mathrm{I}^{\mathrm{Tg}}$ mice. Data are expressed as the mean \pm SD from $8-10$ mice or 3 independent experiments in triplicate. ${ }^{* *} P<0.001$ versus wild-type.

of membrane Klotho, but not sKL, activates $F g f 23$ promoter activity in osteoblast cultures, possibly because of its greater FGF23-mediated induction of ERK activation (see below). Possibly, elevations in $\alpha$-Klotho can stimulate FGF23, as was previously suggested by effects of a translocation in $\alpha$-Klotho gene in humans that increased $\alpha$-Klotho expression and sKL levels, leading to increased circulating FGF23, hyperparathyroidism, and hypophosphatemic rickets (49). Overexpression of $s K L^{130}$ with an adeno-associated virus in mice also leads to a dose-dependent hypophosphatemia and elevation of FGF23 levels $(52,63)$. We failed, however, to observe hypophosphatemia in $K l^{\mathrm{Tg}}$ mice but observed suppression of $1,25(\mathrm{OH})_{2} \mathrm{D}$, increased $C y p 24 a 1$, and reduced Cyp27b1, consistent with the combined actions of canonical FGF23/FGFR/mKL ${ }^{135}(21-24)$ and PTH in the kidney. The lack of FGF23-mediated hypophosphatemia may be due to normal expression of Npt2a in the kidney due to the offsetting effects of reduced PTH to increase renal phosphate reabsorption in $K^{\mathrm{Tg}}$ mice.

The observed reduction in PTH in $K^{\mathrm{Ig}}$ mice was unexpected because hyperparathyroidism was observed in humans with the translocation leading to increased sKL, and elevations in FGF23 are associated with increased PTH in Hyp mice and patients with X-linked hypophosphatemia. However, $\alpha$-Klotho is normally expressed in the parathyroid gland, and studies showing that FGF23 activation of FGFR/mKL ${ }^{135}$ signaling suppresses PTH $(55,56,64)$ are consistent with our results.

Surprisingly, despite the purported role of FGF23 and $\alpha$-Klotho to inhibit osteoblast function and bone mineralization, we did not observe any evidence of rickets, impaired bone formation, or defective mineralization in $K^{\mathrm{Tg}}$ mice, which differs from rickets and osteomalacia reported in human $\alpha$-Klotho translocation with elevated FGF23 (49). The lack of hypophosphatemia, reductions in PTH, and wide tissue expression of $\alpha$-Klotho may contribute to the failure to observe effects of FGF23 and $\alpha$-Klotho on bone in $K l^{\mathrm{Tg}}$ mice. 
A
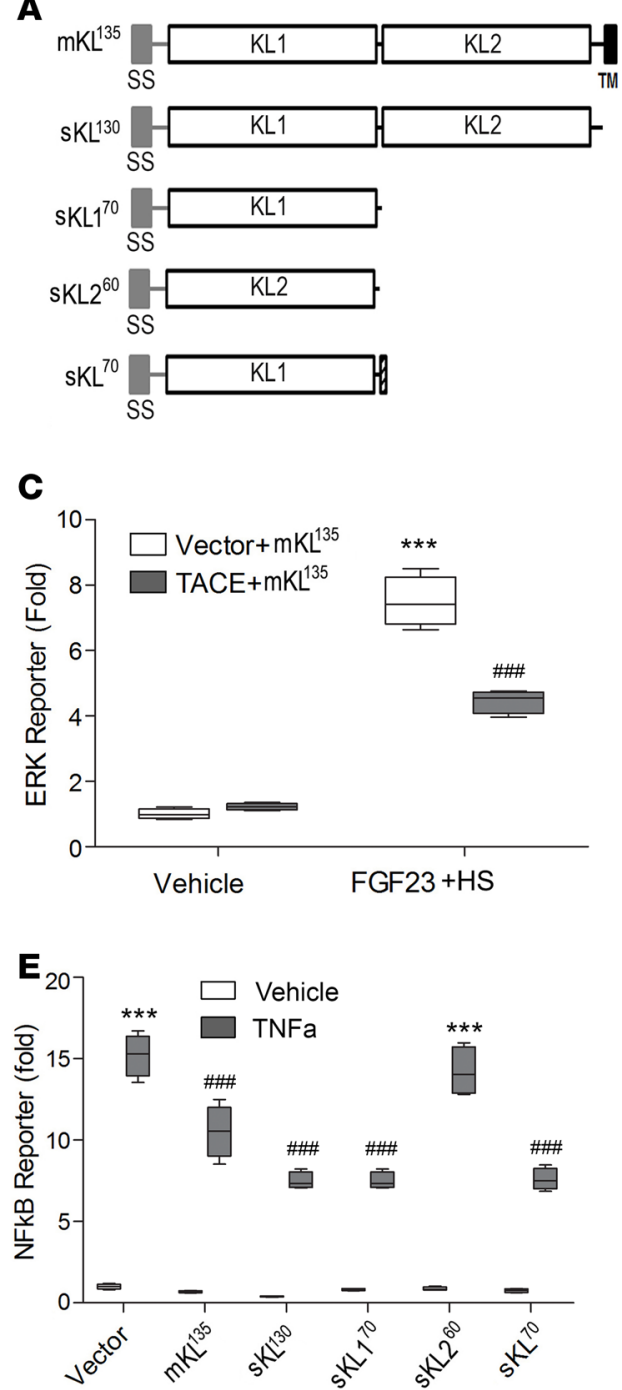
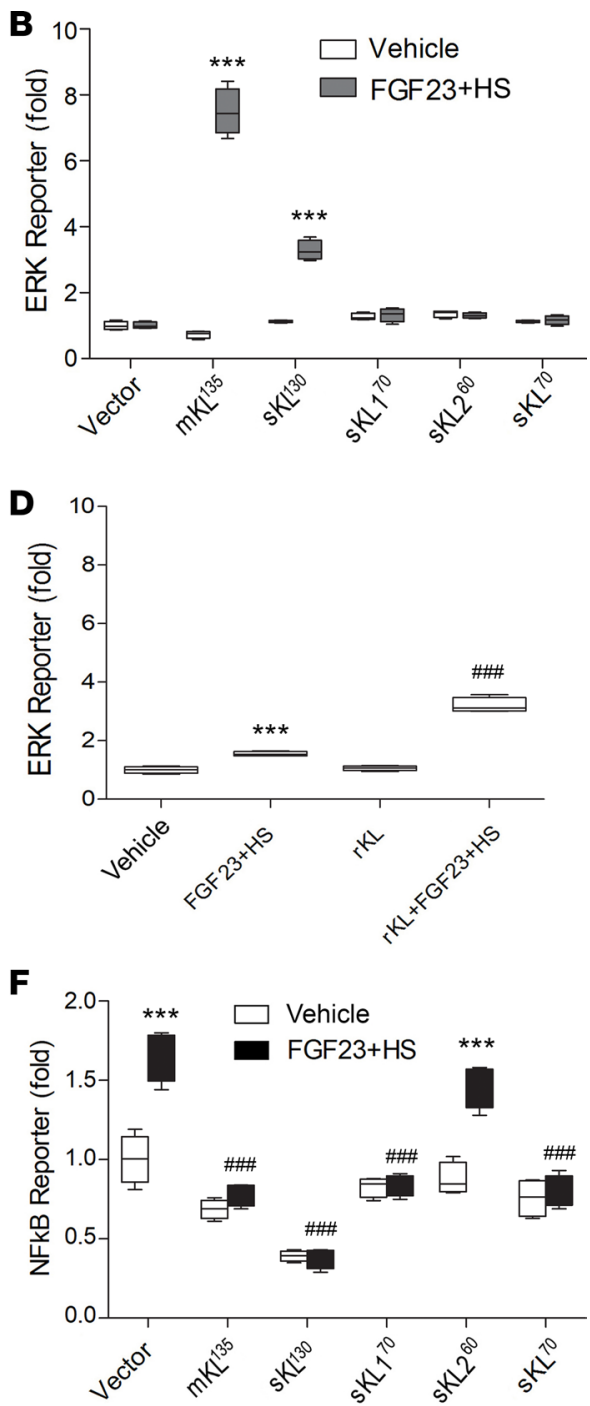

Figure 5. Effects of different $\alpha$-Klotho isoforms on FGF23-mediated activation of ERK activities. (A) Schematic illustration of $\alpha$-Klotho isoform constructs. (B) Cotransfection of different $\alpha$-Klotho isoform constructs with $E R K$ reporter. (C) Cotransfection of $m K L^{135}$ with TACE (ADAM17) cDNA. (D) Addition of recombinant $\alpha$-Klotho ( $\mathrm{rKL}$ ) into HEK293T cells transfected with $E R K$ reporter in response to FGF23 plus heparan sulfate (HS) stimulation. (E and $\mathbf{F}) \mathrm{NF}-\mathrm{KB}$ reporter activities. Data are expressed as the mean \pm SD from 3 independent experiments in triplicate. The box plots depict the minimum and maximum values (whiskers), the upper and lower quartiles, and the median. The length of the box represents the interquartile range. ${ }^{* *} P<0.001$ versus vehicle control group. ${ }^{\# \#} P<0.001$ versus vector plus $\mathrm{mKL}^{135}$ or FGF23 plus HS or vector plus TNF- $\alpha$ or vector plus FGF23 and HS group.

Last, the lack of LVH and the prior reports of improved survival of $K l^{\mathrm{Tg}}$ mice are discordant with the presence of hypertension and elevated FGF23 that we found in these mice (1). FGF23-induced hypertension and cardiac toxicity is thought to be mediated in part by renal effects to stimulate sodium reabsorption and suppress renal angiotensin I converting enzyme 2 and $\alpha$-Klotho expression, leading to low levels of aldosterone, hypertension, and $\operatorname{LVH}(47,65)$. These renal actions likely explain the hypertension in $K l^{\mathrm{Ig}}$ mice because elevations of $\mathrm{FGF} 23$ in $K l^{\mathrm{Tg}}$ mice were associated with increased NCC, decreased aldosterone levels, and higher blood pressure in $K l^{\mathrm{Ig}}$ mice. The possibility that the elevations of FGF23 are below a threshold necessary for exerting cardiotoxicity is not consistent with the hypertension in $K l^{\mathrm{Tg}}$ mice.

FGF23 is also purported to induce LVH by direct activation of FGFR4 in the myocardium through activation of PLC- $\gamma$ hypertrophy signals (46). Our findings suggest the lack of LVH in $K l^{\mathrm{Ig}}$ mice may be due to the newly discovered ability of $\mathrm{mKL}^{135}$ or $\mathrm{sKL}^{130}$ to inhibit FGF23 activation of PLC- $\gamma$ signaling through FGFRs. FGF23 is reported to have low affinity for FGFRs in the absence of $\alpha$-Klotho, but the 
A

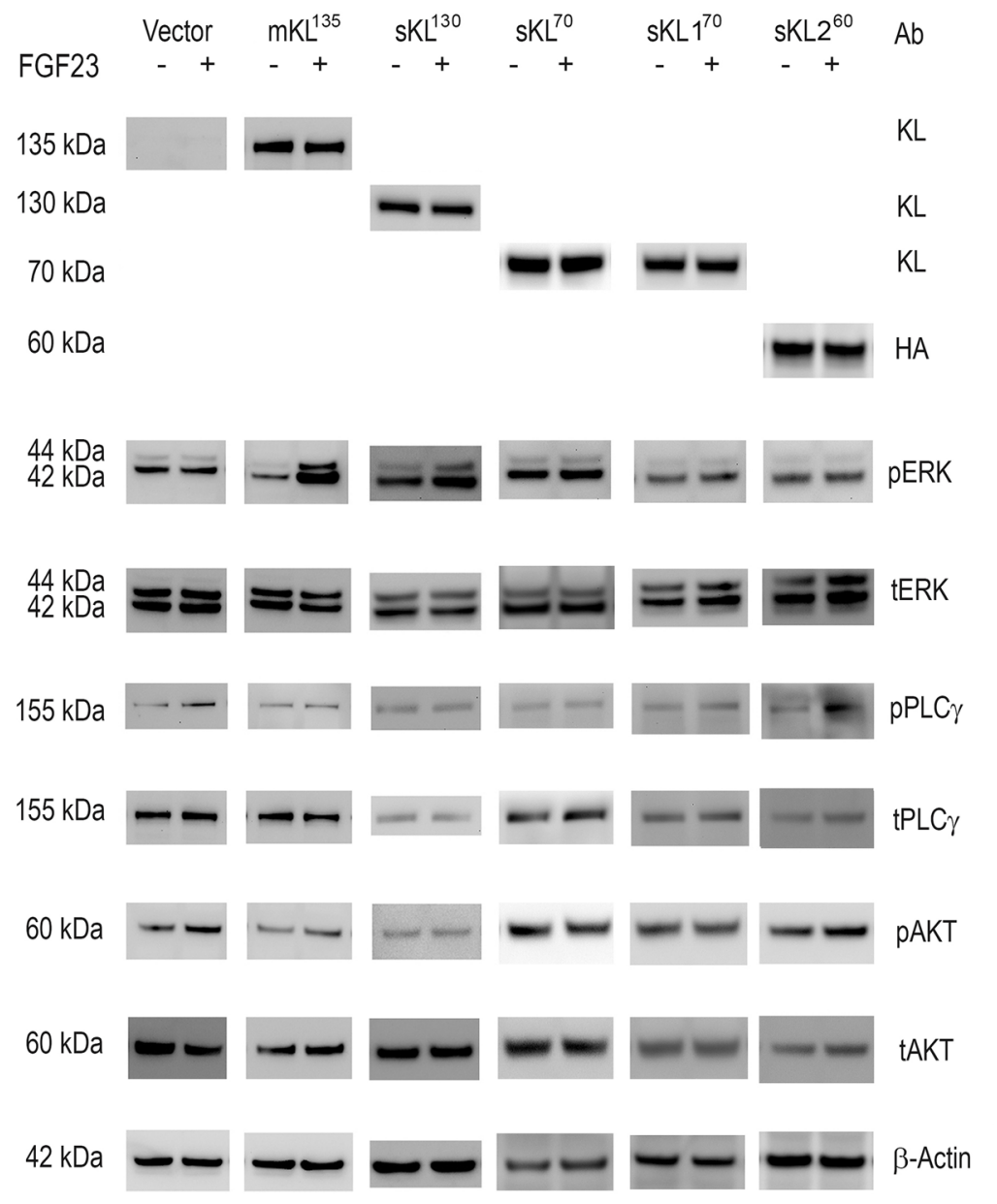

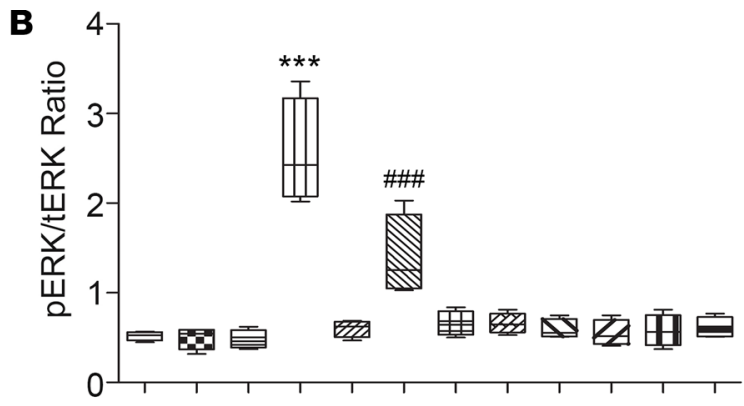
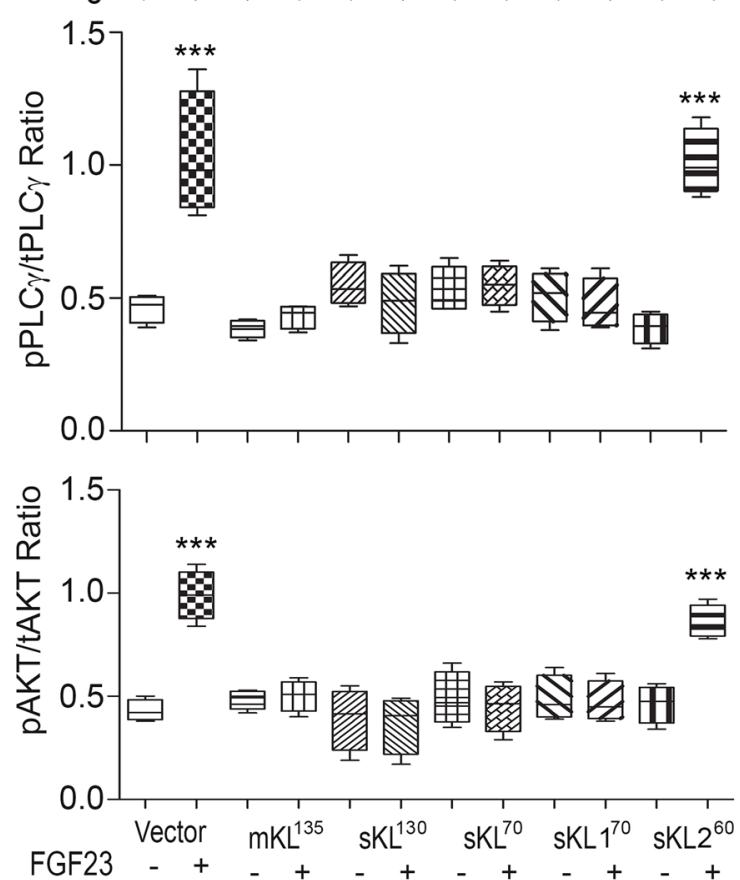

Figure 6. The effects of the FGF23 on FGF23-induced signaling in HEK293T cells transfected with either empty expression vector or human $\alpha$-Klotho isoforms. (A) Western blot analysis of FGF23/ERK, FGF23/PLC- $\gamma$, and FGF23/AKT signaling. Ab, antibody; HA, hemagglutinin tag antibody. (B) Quantification of the pERK/ tERK ratio, pPLC- $\gamma /$ tPLC- $\gamma$ ratio, and pAKT/tAKT ratio. Data are expressed as the mean \pm SD from 3 independent experiments. The box plots depict the minimum and maximum values (whiskers), the upper and lower quartiles, and the median. The length of the box represents the interquartile range. ${ }^{* *} P<0.001$ versus vector plus vehicle or FGF23 group. ${ }^{\# \# P}<0.001$ versus mKL135 plus FGF23 group. t, total.

seminal papers showing that $\mathrm{mKL}^{135}$ is an obligate coreceptor necessary for FGF23 activation of FGFRs only investigated FSR2 $\alpha$-dependent ERK signaling and remarkably did not measure FGF23 activation of PLC- $\gamma$ or PI3K/AKT signaling. Our in vitro studies confirmed FGF23 did not stimulate ERK in the absence of $\alpha$-Klotho $(1,17)$ but also showed that FGF23 in the absence of $\mathrm{mKL}^{135}$ or sKL $\mathrm{L}^{130}$ activates cardiotoxic PLC- $\gamma$ pathways (46). More important, we show that both $\mathrm{mKL}^{135}$ and sKL ${ }^{130}$ inhibited FGF23-induced PLC- $\gamma$ and PI3K/AKT signaling. The ability of sKL to inhibit PLC- $\gamma$ or PI3K/AKT signaling is a potentially novel observation in mammalian systems and is similar to the primordial functions of Klotho to inhibit tyrosine kinase receptor signaling in C. elegans, which lacks FGF23 expression (66).

Our findings also are not in total agreement with the proposal that $\mathrm{sKL}^{130}$ can substitute for $\mathrm{mKL}^{135}$ as a cofactor in FGF23 activation of FGFRs. We found quantitative differences between sKL ${ }^{130}$ and $\mathrm{mKL}^{135}$ effects to promote FGF23-induced ERK signaling, with $\mathrm{mKL}^{135}$ having several-fold greater effects to promote ERK signaling. This suggests that the transmembrane and C-terminus of $\mathrm{mKL}^{135}$ has additional conformational effects to regulate FGFR coupling to ERK.

The current 3D model of FGF23, FGFR1c, and sKL ${ }^{130}$ interactions does not adequately explain the complexity of sKL ${ }^{130}$ and $\mathrm{mKL}^{135}$ effects to bias FGF23 signal transduction through FGFRs (3). Indeed, the mechanisms whereby sKL inhibits FGF23-dependent PLC- $\gamma$ and PI3K/AKT signaling remain to be explained. Recently sKL has been shown to bind with gangliosides containing $\alpha-2-3$-sialyllactose in lipid rafts to inhibit PI3K signaling (19), suggesting one possible mechanism. 
There are other mechanisms whereby sKL has cardioprotective effects that are independent from FGF23. These include disrupting IGF-1, TGF- $\beta$, or TNF- $\alpha$ signaling or effects on calcium-permeable TRPC6 channels that prevent development of LVH (20). We also show that $\alpha$-Klotho isoforms containing KL1 domain suppress both FGF23- and TNF- $\alpha$-mediated NF- $\kappa B$ activation, indicating that the KL1 domain may be responsible for some of these FGF23-independent functions $(1,17,18,66-68)$. Indeed, the $\mathrm{KL} 1$ domain of Klotho was reported to bind to retinoic acid inducible gene I to suppress NF- $\kappa \mathrm{B}$ signaling (68), and NF- $\mathrm{B}$ activation was linked with many of life span regulators, including insulin/IGF-1, FOXO, SIRT, mTOR, and DNA damage $(69,70)$. It has been reported that FGF23 stimulates TNF- $\alpha$ production (45), and PLC- $\gamma$ phosphorylation involves the activation of NF- $\mathrm{\kappa B}$ signaling (71). Additional studies are needed to explore the potential functional differences in sKL70 (KL1) and sKL130 (KL1 + KL2) proteins and their contribution to the increased longevity in $K l^{\mathrm{Tg}}$ mice.

Because excess $\alpha$-Klotho confers cardiac and renal protection $(72,73)$, we were surprised by the finding that transferring an $\mathrm{Fg} f 23$-null background onto $\mathrm{Kl}^{\mathrm{Tg}}$ mice did not improve survival compared to single $\mathrm{Fg} f 23$ null and $K l^{\mathrm{Tg}}$ mice. Deficiency of $\alpha$-Klotho leads to a shorter life span and multiple adverse effects resembling abnormalities caused by FGF23 deficiency $(2,10,74,75)$. The loss of FGF23/FGFR/KL signaling must override the $\alpha$-Klotho effects that are independent from FGF23 $(1,2)$. FGF23's presence may be needed to observe the increased longevity phenotype in $K l^{\mathrm{Tg}}$ mice. The effect of FGF23 on longevity is often analyzed in a renal failure model, but the current experiments did not examine it in this condition.

Nevertheless, our findings provide additional insights into the pathophysiology of FGF23 and $\alpha$-Klotho by suggesting that the levels of sKL as well as the tissue expression of $\mathrm{mKL}^{135}$, along with levels of circulating FGF23, may determine whether physiological or adverse effects are observed. For example, other studies show that angiotensin II can both enhance cardiac fibrosis (76) and attenuate cardiac hypertrophy in $K l^{\mathrm{Tg}}$ mice (59), possibly due to different roles of membrane and soluble $\alpha$-Klotho isoforms. Typically, models of FGF23-induced LVH have suppression of $\alpha$-Klotho (77), suggesting that cardiotoxicity requires elevated FGF23 and reduced sKL. In $K l^{\mathrm{Ig}}$ mice, the ectopic expression of $m K l^{135}$ in the heart or circulating sKL acting as an "on demand" coreceptor may have attenuated FGF23 cardiotoxicity through reducing PLC- $\gamma$-dependent cardiac hypertrophy pathways $(25,78)$.

In conclusion, $\alpha$-Klotho's effects to extend lifespan occurs in the presence of increased FGF23. Further, our findings indicate that FGF23's physiological functions and toxicity can be differentially modulated by the single-pass $135-\mathrm{kDa}$ transmembrane $\mathrm{mKL}^{135}$ and circulating $\sim 130-\mathrm{kDa} \mathrm{sKL}^{130}$ isoform through stimulation of ERK and inhibition of PLC and PI3K/AKT signaling pathways downstream of FGFRs. The ability of $\alpha$-Klotho to regulate FGF23 expression and its KL1 isoforms to modify FGF23 activation of FGFR signaling pathways provides a new mechanistic understanding of the b1-kidney-cardiac axis regulating mineral and cardiovascular homeostasis. In addition, pharmacological elevation of sKL isoforms may offer a potential approach to attenuate toxicities mediated by excess FGF23 and accentuate FGF23-independent effects of $\alpha$-Klotho.

\section{Methods}

Animal breeding and genotyping. We obtained $K l^{\mathrm{Tg}}$ mice from Makoto Kuro-o (1). These mice overexpress transmembrane Klotho form $\left(m K l^{135}\right)$ under the control of the hEFla. The Fgf23-heterozygous mice $\left(\mathrm{Fg} f \mathrm{3}^{+-}\right)$were created by our laboratory as described previously (53). These mice were bred and maintained on a C57BL/6J background. The mice were anesthetized with ketamine $(90 \mathrm{mg} / \mathrm{kg})$ and xylazine $(10 \mathrm{mg} / \mathrm{kg}$ ) for a bone densitometry scan, and mice not useful for experimental purposes were sacrificed by $\mathrm{CO}_{2}$ inhalation plus cervical dislocation. To examine whether overexpression of $m K l^{135}$ rescues the phenotypes of $\mathrm{Fg} 223$-null mice, we created double-heterozygous $\mathrm{KI} \mathrm{Ig}^{\mathrm{Tg}} \mathrm{Fg} 2 \mathrm{3}^{+/-}$mice. Then double-heterozygous

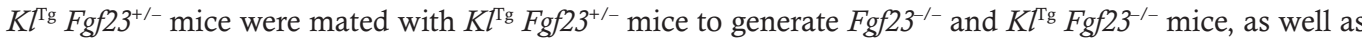
$K l^{\mathrm{Tg}}$ and wild-type mice. These mice were used to count the percentage that survived and collect serum and tissue samples at 8 weeks of age for phenotypic analysis.

$\alpha$-Klotho expression constructs. The human $\alpha$-Klotho membrane (plasmid 17712) and secreted (plasmid 17713) forms were purchased from Addgene. Both human and mouse full-length $\alpha$-Klotho membrane $\left(m K L^{135}\right)$, fulllength $\alpha$-Klotho without intra-cytoplasmic/transmembrane domain $\left(s K L^{130}\right), s K L 1^{70}$ and $s K L 2^{60}$ constructs that contain a signal sequence of the original full-length $\alpha$-Klotho, and secreted $\alpha$-Klotho $\left(s K L^{70}\right)$ were gifts from Tami Rubinek and Ido Wolf (Sourasky Medical Center, Tel Aviv, Israel). For FGF23-mediated activation of the FGFR/KL complex, HEK293T cells (ATCC) were transiently transfected with either empty expression vector or various Klotho expression constructs along with the ERK luciferase reporter system (11) and Renilla 
luciferase-null (Promega) as an internal control plasmid. For TNF- $\alpha-$ mediated activation of the NF- $\mathrm{kB}$ signaling pathway, HEK293T cells were transiently transfected with either empty expression vector or various Klotho expression constructs along with the NF-кB luciferase reporter plasmid (pNiFty-Luc, InvivoGen) and Renilla luciferase-null as an internal control plasmid. For the effects of ADAM17-mediated (TACE-mediated) ectodomain cleavage of full-length membrane $\alpha$-Klotho on FGF23 signaling, HEK293T cells were transiently transfected with either empty expression vector or TACE expression construct along with membrane $\alpha$-Klotho, the ERK luciferase reporter, and Renilla luciferase-null as an internal control plasmid. Transfections were performed by electroporation using Cell Line Nucleofector Kit R according to the manufacturer's protocol (Amaxa Inc.). Thirty-six hours after transfection, the transfected cells were treated with the test compound in the presence or absence of $1 \mathrm{nM}$ FGF23. After 5 hours, the cells were lysed, and luciferase activities were measured using a Synergy H4 Hybrid Multi-Mode Microplate Reader and Promega Dual-Luciferase Reporter Assay System.

Bone densitometry, histomorphometric, and micro-CT analysis. BMD of femurs was assessed at 8 weeks of age using a small-animal bone densitometer (Lunar Corp). Calcein (MilliporeSigma) double labeling of bone and histomorphometric analyses of periosteal MAR in tibias were performed using the osteomeasure analysis system (Osteometrics, Inc.). The distal femoral metaphyses were also scanned using a micro-CT 40 scanner (Scanco Medical AG). A 3D image analysis was done to determine bone volume (bone volume/total volume) and cortical thickness as previously described $(79,80)$.

Echocardiography and blood pressure measurement. Noninvasive ultrasound examination of the cardiovascular system was performed using a Vevo 2100 Ultrasound System (VisualSonics Inc.) following standard procedures. Blood pressure was measured using mouse tail cuff technique (CODA, Kent Scientific) as described previously $(65,81,82)$.

Real-time RT-PCR. For quantitative real-time RT-PCR, $1.0 \mu \mathrm{g}$ total RNA isolated from the heart, kidney, or long bone of 8-week-old mice was reverse-transcribed as previously described (83, 84). PCR reactions contained $100 \mathrm{ng}$ template (cDNA or RNA), $300 \mathrm{nM}$ each forward and reverse primers, and $1 \mathrm{XqP}$ CR Supermix (Bio-Rad) in $50 \mu \mathrm{L}$. The threshold cycle $(\mathrm{Ct})$ of tested gene product from the indicated genotype was normalized to the $\mathrm{Ct}$ for cyclophilin A. Expression of total Klotho isoform transcripts was performed using the following Klotho isoform-specific primers: forward primer of mouse $m K L^{135}$ transcript, 5'-CATTTCCCTGTGACTTTGCTTG-3', and reverse primer, 5'-ATGCACATCCCACAGATAGAC-3'; forward primer of mouse $s-K L^{70}$ transcript, 5'-GAGTCAGGACAAGGAGCTGT-3', and reverse primer, 5'-GGCCGACACTGGGTTTTG-3'. The sequences of primers for kidney and bone gene transcripts were previously reported $(83,84)$. In addition, the fold change of tested gene transcripts was calculated from the relative levels of the normal gene transcripts in wild-type mice.

Immunoprecipitation of serum soluble Klotho proteins. Soluble Klotho protein in serum was immunoprecipitated and detected by Western blotting as described with modifications (10). Mouse serum (0.1 mL) was mixed with $10 \mu \mathrm{L} 10 \%$ SDS and heated at $100^{\circ} \mathrm{C}$ for 4 minutes; then, it was diluted with $0.4 \mathrm{~mL} 1 \%$ Triton $\mathrm{X}-100$ in PBS (pH 7.4) and centrifuged at 20,000 $\mathrm{g}$ for 4 minutes. The resulting supernatant was incubated with $2 \mu \mathrm{g}$ anti-Klotho $\mathrm{KL} 1 \mathrm{rat} \mathrm{mAb}(\mathrm{KL}-234)$ at $4^{\circ} \mathrm{C}$ overnight and then incubated with $20 \mu \mathrm{L}$ protein-G Agarose (Thermo Fisher Scientific) at $4^{\circ} \mathrm{C}$ for 2 hours for precipitation. The precipitate was washed 3 times with 1\% Triton X-100 in PBS (pH 7.4) and once with PBS ( $\mathrm{pH} 7.4$ ), mixed with SDS-PAGE sample buffer, and subjected to $8 \%$ SDS-PAGE. After transferring onto a nitrocellulose membrane, Klotho was detected using anti-Klotho rat mAb (KM2076, TransGenic Inc.) (85) or anti-Klotho KL1 rat mAb (KL-234, provided by Gwendalyn D. King at University of Alabama at Birmingham, Birmingham, Alabama, USA) (86), and the density of immunoreactive Klotho bands was analyzed by ImageJ software (NIH).

Serum biochemistry. Serum soluble Klotho was determined using a Klotho ELISA kit from CEDARLANE. Calcium was measured using a calcium cresolphthalein complexone kit (Stanbio Laboratories), and phosphorus was measured using the phosphomolybdylate-ascorbic acid method, as previously described $(83,87,88)$. Serum PTH levels were measured using the Mouse Intact PTH ELISA kit (Immutopics). Serum full-length FGF23 levels were measured using the FGF23 ELISA kit (Kainos Laboratories). Serum 1,25(OH) 2 D levels were measured using the Vitamin D EIA kit (Immunodiagnostic Systems).

FGF23 reporter activity. The MC3T3-E1 osteoblasts were cultured in $\alpha$-MEM containing $10 \%$ fetal bovine serum and $1 \%$ penicillin/streptomycin. To examine whether Klotho isoforms regulate FGF-23 transcription, $1 \times 10^{6}$ of the MC3T3-E1 osteoblasts were transfected with $2.0 \mu \mathrm{g}$ of $0.6-\mathrm{kb} \mathrm{Fg} 23$ promoter-luciferase reporter (Fgf23 reporter) constructs in combination with $1.0 \mu \mathrm{g}$ of empty pcDNA3.1 expression vector or Klotho isoform plasmids, and $0.6 \mu \mathrm{g}$ of Renilla luciferase-null as an internal control plasmid, by electroporation using 
a cell line optimal transfection kit according to the manufacturer's protocol (Amaxa Inc.). A total of $3.6 \mu \mathrm{g}$ of plasmid DNAs was used for each electroporation. The transfected cells were plated in 12-well plates and harvested 32 hours after transfection. Cells were lysed in $100 \mu \mathrm{L}$ of reporter lysis buffer (Promega). A luciferase assay (20 $\mu \mathrm{L}$ of cells lysed) was performed using a Synergy H4 Hybrid Multi-Mode Microplate Reader and Promega Dual-Luciferase Reporter Assay System.

Western blot analysis. Kidneys from wild-type and $K^{\mathrm{Ig}}$ mice were homogenized into a fine powder in liquid nitrogen using a porcelain mortar and pestle. The powder was transferred into T-PER Tissue Protein Extraction Reagent with $1 \times$ Halt protease inhibitor (Thermo Fisher Scientific) and $1 \mathrm{mM}$ phenylmethylsulfonyl fluoride (PMSF). After three 30-second sonications, samples were centrifuged at 13,000 $\mathrm{g}$ for $10 \mathrm{~min}$ utes, and supernatants were stored at $-80^{\circ} \mathrm{C}$ until use. Similarly, HEK293T cells transfected with human $m K L^{135}, s K L^{130}, s K L^{70}, s K L 1^{70}$, or $s K L 2^{60}$ were lysed with $150 \mu \mathrm{L}$ of M-PER Cell Protein Extraction Reagent (Pierce Biotechnology, Thermo Fisher Scientific) with $1 \times$ Halt protease inhibitor and $1 \mathrm{mM}$ PMSF per well. After three 30-second sonications, whole-cell lysates were centrifuged at 13,000 $\mathrm{g}$ for 10 minutes, and supernatants were stored at $-80^{\circ} \mathrm{C}$ until use. Protein concentrations of the supernatant were determined with a total protein assay kit (Bio-Rad). Equal quantities of protein were subjected to $4 \%-12 \%$ Bis-Tris gradient gels (Invitrogen, Thermo Fisher Scientific) and were analyzed with standard Western blot protocols (HRP-conjugated secondary antibodies from Santa Cruz Biotechnology [sc-2006] and ECL chemiluminescent immunodetection system from GE Healthcare Bio-Sciences). Anti-Klotho KL1 rat mAb (KM2076) and anti-Klotho KL2 rat mAb (KM2119) were purchased from TransGenic Inc. (85). Anti-Klotho KL1 rat mAb (KL-234) was provided by Gwendalyn D. King at University of Alabama at Birmingham (USA) (86). HA Tag mAb (26183-HRP) was purchased from Thermo Fisher Scientific. Anti-phospho-ERK1/2 (Thr202/Tyr204) (D13.14.4E, catalog 4370), anti-ERK1/2 (catalog 9102), anti-phospho-PLC $\gamma 1$ (D25A9, catalog 8713), anti-PLC $\gamma 1$ (catalog 2822), anti-phospho-Akt (D9E, catalog 4060), and anti-Akt (catalog 9272) were purchased from Cell Signaling Technologies. Anti- $\beta$-actin (sc-47778) antibody was purchased from Santa Cruz Biotechnology. The intensity of bands was quantified using ImageJ software.

Statistics. We evaluated differences between 2 groups by unpaired 2-tailed $t$ test and multiple groups by 1 -way ANOVA with Newman-Keuls multiple-comparisons test. All values are expressed as mean \pm SD. All computations were performed using a commercial biostatistics software (Prism by GraphPad Software Inc.). $P$ value less than 0.05 was considered significant.

Study approval. All animal research was conducted according to guidelines provided by the National Institutes of Health (NIH) and the Institute of Laboratory Animal Resources, National Research Council. The University of Tennessee Health Science Center's Animal Care and Use Committee approved all animal studies (protocol 18-111.0).

\section{Author contributions}

ZX and LDQ wrote the manuscript. ZX, GK, SM, UM, LC, and CC performed the in vitro and in vivo experimental studies. ZX, GK, SM, and LDQ guided the research and reviewed and edited the manuscript.

\section{Acknowledgments}

This work was supported by grant R01-AR045955 to LDQ from the NIH. We thank Tami Rubinek and Ido Wolf for providing the Klotho constructs in this study.

Address correspondence to: Leigh Darryl Quarles, Coleman College of Medicine Building, Suite B216, University of Tennessee Health Science Center, 956 Court Avenue, Memphis, Tennessee 38163, USA. Phone: 901.448.1459; Email: dquarles@uthsc.edu.

1. Kurosu H, et al. Suppression of aging in mice by the hormone Klotho. Science. 2005;309(5742):1829-1833.

2. Kuro-o M, et al. Mutation of the mouse klotho gene leads to a syndrome resembling ageing. Nature. 1997;390(6655):45-51.

3. Chen G, et al. $\alpha$-Klotho is a non-enzymatic molecular scaffold for FGF23 hormone signalling. Nature. 2018;553(7689):461-466.

4. Matsumura Y, Aizawa H, Shiraki-Iida T, Nagai R, Kuro-o M, Nabeshima Y. Identification of the human klotho gene and its 2 transcripts encoding membrane and secreted klotho protein. Biochem Biophys Res Commun. 1998;242(3):626-630.

5. Mencke R, et al. Human alternative Klotho mRNA is a nonsense-mediated mRNA decay target inefficiently spliced in renal disease. JCI Insight. 2017;2(20):94375.

6. Massó A, et al. Secreted and transmembrane $\alpha$ Klotho isoforms have different spatio-temporal profiles in the brain during aging and Alzheimer's disease progression. PLoS ONE. 2015;10(11):e0143623. 
7. Massó A, Sánchez A, Bosch A, Giménez-Llort L, Chillón M. Secreted $\alpha$ Klotho isoform protects against age-dependent memory deficits. Mol Psychiatry. 2018;23(9):1937-1947.

8. Polanska UM, Edwards E, Fernig DG, Kinnunen TK. The cooperation of FGF receptor and Klotho is involved in excretory canal development and regulation of metabolic homeostasis in Caenorhabditis elegans. J Biol Chem. 2011;286(7):5657-5666

9. Bloch L, et al. Klotho is a substrate for alpha-, beta- and gamma-secretase. FEBS Lett. 2009;583(19):3221-3224.

10. Xie J, Yoon J, An SW, Kuro-o M, Huang CL. Soluble Klotho protects against uremic cardiomyopathy independently of fibroblast growth factor 23 and phosphate. J Am Soc Nephrol. 2015;26(5):1150-1160.

11. Akimoto T, et al. Characteristics of urinary and serum soluble Klotho protein in patients with different degrees of chronic kidney disease. BMC Nephrol. 2012;13:155.

12. Imura A, et al. Secreted Klotho protein in sera and CSF: implication for post-translational cleavage in release of Klotho protein from cell membrane. FEBS Lett. 2004;565(1-3):143-147.

13. Hum JM, O'Bryan L, Smith RC, White KE. Novel functions of circulating Klotho. Bone. 2017;100:36-40.

14. Abramovitz L, et al. KL1 internal repeat mediates klotho tumor suppressor activities and inhibits bFGF and IGF-I signaling in pancreatic cancer. Clin Cancer Res. 2011;17(13):4254-4266.

15. Maekawa Y, et al. Klotho suppresses TNF-alpha-induced expression of adhesion molecules in the endothelium and attenuates NF-kappaB activation. Endocrine. 2009;35(3):341-346.

16. Dalton GD, Xie J, An SW, Huang CL. New insights into the mechanism of action of soluble Klotho. Front Endocrinol (Lausanne). 2017;8:323.

17. Doi S, et al. Klotho inhibits transforming growth factor-beta1 (TGF-beta1) signaling and suppresses renal fibrosis and cancer metastasis in mice. J Biol Chem. 2011;286(10):8655-8665.

18. Liu H, et al. Augmented Wnt signaling in a mammalian model of accelerated aging. Science. 2007;317(5839):803-806.

19. Wright JD, et al. Modeled structural basis for the recognition of $\alpha 2$-3-sialyllactose by soluble Klotho. FASEB J. 2017;31(8):3574-3586.

20. Schlondorff J. TRPC6 and kidney disease: sclerosing more than just glomeruli? Kidney Int. 2017;91(4):773-775.

21. Martin A, David V, Quarles LD. Regulation and function of the FGF23/klotho endocrine pathways. Physiol Rev. 2012;92(1):131-155.

22. Quarles LD. FGF23, PHEX, and MEPE regulation of phosphate homeostasis and skeletal mineralization. Am J Physiol Endocrinol Metab. 2003;285(1):E1-E9.

23. Quarles LD. The bone and beyond: 'dem bones' are made for more than walking. Nat Med. 2011;17(4):428-430.

24. Quarles LD. Endocrine functions of bone in mineral metabolism regulation. J Clin Invest. 2008;118(12):3820-3828.

25. Urakawa I, et al. Klotho converts canonical FGF receptor into a specific receptor for FGF23. Nature. 2006;444(7120):770-774

26. Kurosu H, et al. Regulation of fibroblast growth factor-23 signaling by klotho. J Biol Chem. 2006;281(10):6120-6123.

27. Nakatani T, et al. In vivo genetic evidence for klotho-dependent, fibroblast growth factor 23 (Fgf23) -mediated regulation of systemic phosphate homeostasis. FASEB J. 2009;23(2):433-441.

28. Liu S, et al. Fibroblast growth factor 23 is a counter-regulatory phosphaturic hormone for vitamin D. J Am Soc Nephrol. 2006;17(5):1305-1315.

29. Shimada T, et al. FGF-23 is a potent regulator of vitamin D metabolism and phosphate homeostasis. JBone Miner Res. 2004;19(3):429-435.

30. Tomiyama K, et al. Relevant use of Klotho in FGF19 subfamily signaling system in vivo. Proc Natl Acad Sci USA. 2010;107(4):1666-1671.

31. Han X, Yang J, Li L, Huang J, King G, Quarles LD. Conditional deletion of Fgfr1 in the proximal and distal tubule identifies distinct roles in phosphate and calcium transport. PLOS ONE. 2016;11(2):e0147845.

32. Gattineni J, Alphonse P, Zhang Q, Mathews N, Bates CM, Baum M. Regulation of renal phosphate transport by FGF23 is mediated by FGFR1 and FGFR4. Am J Physiol Renal Physiol. 2014;306(3):F351-F358.

33. Andrukhova O, et al. Klotho lacks an FGF23-independent role in mineral homeostasis. J Bone Miner Res. 2017;32(10):2049-2061.

34. Han X, Quarles LD. Multiple faces of fibroblast growth factor-23. Curr Opin Nephrol Hypertens. 2016;25(4):333-342.

35. Urakawa I, et al. Klotho converts canonical FGF receptor into a specific receptor for FGF23. Nature. 2006;444(7120):770-774.

36. Gutiérrez OM, et al. Fibroblast growth factor 23 and mortality among patients undergoing hemodialysis. NEngl J Med. 2008;359(6):584-592

37. Brandenburg VM, et al. Fibroblast growth factor 23 (FGF23) and mortality: the Ludwigshafen Risk and Cardiovascular Health Study. Atherosclerosis. 2014;237(1):53-59.

38. Souma N, et al. Fibroblast growth factor 23 and cause-specific mortality in the general population: The Northern Manhattan Study. J Clin Endocrinol Metab. 2016;101(10):3779-3786

39. Gutiérrez OM, et al. Fibroblast growth factor 23 and left ventricular hypertrophy in chronic kidney disease. Circulation. 2009;119(19):2545-2552.

40. Isakova $\mathrm{T}$, et al. Fibroblast growth factor 23 and risks of mortality and end-stage renal disease in patients with chronic kidney disease. JAMA. 2011;305(23):2432-2439.

41. Hsu HJ, Wu MS. Fibroblast growth factor 23: a possible cause of left ventricular hypertrophy in hemodialysis patients. $A m J$ Med Sci. 2009;337(2):116-122.

42. Jean G, et al. Peripheral vascular calcification in long-haemodialysis patients: associated factors and survival consequences. Nephrol Dial Transplant. 2009;24(3):948-955.

43. Munoz Mendoza J, et al. Fibroblast growth factor 23 and inflammation in CKD. Clin J Am Soc Nephrol. 2012;7(7):1155-1162.

44. Hanks LJ, Casazza K, Judd SE, Jenny NS, Gutiérrez OM. Associations of fibroblast growth factor-23 with markers of inflammation, insulin resistance and obesity in adults. PLOS ONE. 2015;10(3):e0122885.

45. Han X, Li L, Yang J, King G, Xiao Z, Quarles LD. Counter-regulatory paracrine actions of FGF-23 and 1,25(OH)2 D in macrophages. FEBS Lett. 2016;590(1):53-67.

46. Grabner A, et al. Activation of cardiac fibroblast growth factor receptor 4 causes left ventricular hypertrophy. Cell Metab. 2015;22(6):1020-1032.

47. Andrukhova O, et al. FGF23 regulates renal sodium handling and blood pressure. EMBO Mol Med. 2014;6(6):744-759.

48. Faul C, et al. FGF23 induces left ventricular hypertrophy. J Clin Invest. 2011;121(11):4393-4408. 
49. Brownstein CA, et al. A translocation causing increased alpha-klotho level results in hypophosphatemic rickets and hyperparathyroidism. Proc Natl Acad Sci USA. 2008;105(9):3455-3460.

50. Komaba H, et al. Klotho expression in osteocytes regulates bone metabolism and controls bone formation. Kidney Int. 2017;92(3):599-611

51. Kaludjerovic J, et al. Klotho expression in long bones regulates FGF23 production during renal failure. FASEB J. 2017;31(5):2050-2064.

52. Smith RC, et al. Circulating $\alpha$ Klotho influences phosphate handling by controlling FGF23 production. J Clin Invest. 2012;122(12):4710-4715.

53. Liu S, Zhou J, Tang W, Jiang X, Rowe DW, Quarles LD. Pathogenic role of Fgf23 in Hyp mice. Am J Physiol Endocrinol Metab. 2006;291(1):E38-E49.

54. Olauson $\mathrm{H}$, et al. Targeted deletion of Klotho in kidney distal tubule disrupts mineral metabolism. J Am Soc Nephrol. 2012;23(10):1641-1651.

55. Krajisnik T, et al. Fibroblast growth factor-23 regulates parathyroid hormone and 1alpha-hydroxylase expression in cultured bovine parathyroid cells. J Endocrinol. 2007;195(1):125-131.

56. Ben-Dov IZ, et al. The parathyroid is a target organ for FGF23 in rats. J Clin Invest. 2007;117(12):4003-4008.

57. Faul C. Cardiac actions of fibroblast growth factor 23. Bone. 2017;100:69-79.

58. Yu L, Meng W, Ding J, Cheng M. Klotho inhibits angiotensin II-induced cardiomyocyte hypertrophy through suppression of the AT1R/beta catenin pathway. Biochem Biophys Res Commun. 2016;473(2):455-461

59. Ding J, et al. Klotho inhibits angiotensin II-induced cardiac hypertrophy, fibrosis, and dysfunction in mice through suppression of transforming growth factor- $\beta 1$ signaling pathway. Eur J Pharmacol. 2019;859:172549.

60. Chihara Y, et al. Klotho protein promotes adipocyte differentiation. Endocrinology. 2006;147(8):3835-3842.

61. Fan J, Sun Z. The antiaging gene Klotho regulates proliferation and differentiation of adipose-derived stem cells. Stem Cells. 2016;34(6):1615-1625.

62. Xiao Z, et al. A computationally identified compound antagonizes excess FGF-23 signaling in renal tubules and a mouse model of hypophosphatemia. Sci Signal. 2016;9(455):ra113.

63. Hum JM, et al. Chronic hyperphosphatemia and vascular calcification are reduced by stable delivery of soluble Klotho. $J A m$ Soc Nephrol. 2017;28(4):1162-1174.

64. Silver J, Naveh-Many T. FGF23 and the parathyroid glands. Pediatr Nephrol. 2010;25(11):2241-2245.

65. Pi M, et al. Cardiovascular interactions between fibroblast growth factor-23 and angiotensin ii. Sci Rep. 2018;8(1):12398

66. Château MT, Araiz C, Descamps S, Galas S. Klotho interferes with a novel FGF-signalling pathway and insulin/Igf-like signalling to improve longevity and stress resistance in Caenorhabditis elegans. Aging (Albany NY). 2010;2(9):567-581.

67. Zeng Y, Wang PH, Zhang M, Du JR. Aging-related renal injury and inflammation are associated with downregulation of Klotho and induction of RIG-I/NF-кB signaling pathway in senescence-accelerated mice. Aging Clin Exp Res. 2016;28(1):69-76

68. Liu F, Wu S, Ren H, Gu J. Klotho suppresses RIG-I-mediated senescence-associated inflammation. Nat Cell Biol. 2011;13(3):254-262.

69. Salminen A, Ojala J, Huuskonen J, Kauppinen A, Suuronen T, Kaarniranta K. Interaction of aging-associated signaling cascades: inhibition of NF-kappaB signaling by longevity factors FoxOs and SIRT1. Cell Mol Life Sci. 2008;65(7-8):1049-1058.

70. Tilstra JS, Clauson CL, Niedernhofer LJ, Robbins PD. NF-אB in aging and disease. Aging Dis. 2011;2(6):449-465.

71. Schulze-Luehrmann J, Ghosh S. Antigen-receptor signaling to nuclear factor kappa B. Immunity. 2006;25(5):701-715.

72. Hu MC, et al. Recombinant $\alpha$-Klotho may be prophylactic and therapeutic for acute to chronic kidney disease progression and uremic cardiomyopathy. Kidney Int. 2017;91(5):1104-1114.

73. Hui $\mathrm{H}$, et al. Klotho suppresses the inflammatory responses and ameliorates cardiac dysfunction in aging endotoxemic mice. Oncotarget. 2017;8(9):15663-15676.

74. Tsujikawa H, Kurotaki Y, Fujimori T, Fukuda K, Nabeshima Y. Klotho, a gene related to a syndrome resembling human premature aging, functions in a negative regulatory circuit of vitamin D endocrine system. Mol Endocrinol. 2003;17(12):2393-2403.

75. Xie J, Cha SK, An SW, Kuro-OM, Birnbaumer L, Huang CL. Cardioprotection by Klotho through downregulation of TRPC6 channels in the mouse heart. Nat Commun. 2012;3:1238.

76. Liu X, et al. Differential regulatory role of soluble klothos on cardiac fibrogenesis in hypertension. Am J Hypertens. 2016;29(10):1140-1147.

77. Shalhoub V, et al. FGF23 neutralization improves chronic kidney disease-associated hyperparathyroidism yet increases mortality. J Clin Invest. 2012;122(7):2543-2553.

78. Planavila A, Redondo-Angulo I, Villarroya F. FGF21 and cardiac physiopathology. Front Endocrinol (Lausanne). $2015 ; 6: 133$.

79. Xiao Z, Zhang S, Cao L, Qiu N, David V, Quarles LD. Conditional disruption of Pkd1 in osteoblasts results in osteopenia due to direct impairment of bone formation. J Biol Chem. 2010;285(2):1177-1187.

80. Xiao Z, Zhang S, Magenheimer BS, Luo J, Quarles LD. Polycystin-1 regulates skeletogenesis through stimulation of the osteoblast-specific transcription factor RUNX2-II. J Biol Chem. 2008;283(18):12624-12634.

81. Han X, et al. Cardiovascular effects of renal distal tubule deletion of the FGF receptor 1 gene. J Am Soc Nephrol. 2018;29(1):69-80.

82. Parks C, Alam MA, Sullivan R, Mancarella S. STIM1-dependent Ca(2+) microdomains are required for myofilament remodeling and signaling in the heart. Sci Rep. 2016;6:25372.

83. Qiu N, Xiao Z, Cao L, David V, Quarles LD. Conditional mesenchymal disruption of pkd1 results in osteopenia and polycystic kidney disease. PLoS ONE. 2012;7(9):e46038.

84. Qiu N, Zhou H, Xiao Z. Downregulation of PKD1 by shRNA results in defective osteogenic differentiation via cAMP/PKA pathway in human MG-63 cells. J Cell Biochem. 2012;113(3):967-976.

85. Kato Y, et al. Establishment of the anti-Klotho monoclonal antibodies and detection of Klotho protein in kidneys. Biochem Biophys Res Commun. 2000;267(2):597-602.

86. Maltare A, et al. Development and characterization of monoclonal antibodies to detect klotho. Monoclon Antib Immunodiagn Immunother. 2014;33(6):420-427.

87. Qiu N, Cao L, David V, Quarles LD, Xiao Z. Kif3a deficiency reverses the skeletal abnormalities in Pkd1 deficient mice by restoring the balance between osteogenesis and adipogenesis. PLoS ONE. 2010;5(12):e15240.

88. Xiao Z, et al. Selective Runx2-II deficiency leads to low-turnover osteopenia in adult mice. Dev Biol. 2005;283(2):345-356. 